Canadian

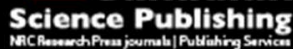

Canadian Journal of Civil Engineering Revue canadienne de génie civil

\title{
Conflicts Resolution based Construction Temporary Facilities Layout Planning in Large-scale Construction Projects
}

\begin{tabular}{|r|l|}
\hline Journal: & Canadian Journal of Civil Engineering \\
\hline Manuscript ID & cjce-2015-0144.R1 \\
\hline Danuscript Type: & Article \\
\hline Complete List of Authors: & $\begin{array}{l}\text { Song, Xiaoling; Sichuan University, Department of Management Science } \\
\text { and Engineering; Columbia University, Department of Civil Engineering and } \\
\text { Engineering Mechanics } \\
\text { Xu, Jiuping; Sichuan University, Business School; Sichuan University, State } \\
\text { Key Laboratory of Hydraulics and Mountain River Engineering } \\
\text { Shen, Charles; Columbia University, Department of Civil Engineering and } \\
\text { Engineering Mechanics } \\
\text { Peña-Mora, Feniosky; Columbia University, Department of Civil Engineering } \\
\text { and Engineering Mechanics }\end{array}$ \\
\hline Keyword: & \begin{tabular}{l} 
CTFLP, TRP, large-scale construction projects, MINBLPM, HGABPSO \\
\hline
\end{tabular} \\
\hline \multicolumn{2}{|c}{} \\
\hline
\end{tabular}


Conflicts Resolution based Construction Temporary Facilities Layout Planning in Large-scale Construction Projects

\author{
Xiaoling Song ${ }^{1,2}$, Jiuping $\mathrm{Xu}^{1,3^{*}}$, Charles Shen ${ }^{2}$, Feniosky Peña-Mora ${ }^{2}$ \\ ${ }^{1}$ Uncertainty Decision-Making Laboratory, Sichuan University, Chengdu 610064, P. R. China; \\ ${ }^{2}$ Advanced ConsTruction and InfOrmation techNology (ACTION) Laboratory, Department of Civil Engineering and Engineering \\ Mechanics, Columbia University, New York 10027, USA; \\ ${ }^{3}$ State Key Laboratory of Hydraulics and Mountain River Engineering, Sichuan University, Chengdu 610064, P. R. China.
}

* Corresponding author. Tel.:+86-028-85418522. E-mail address: xujiuping@scu.edu.cn. 


\begin{abstract}
The construction temporary facilities layout planning (CTFLP) is important and complex in large-scale construction projects. During the CTFLP process, the general contractor has conflicts with many subcontractors regarding other pre-planning tasks, such as the transport routes planning (TRP). The resolution of the conflicts is crucial and this study attempts to determine the CTFLP considering conflicts resolution. Specifically, a novel methodology based on conflicts resolution between the CTFLP and the TRP is proposed, which can be adapted for future CTFLP based on resolving other types of conflicts. The two procedures-based methodology is composed of a bi-level model (MINBLPM) and a solution approach (HGABPSO). The methodology is applied to a dam construction project in China to test the applicability, and the results show that it is able to obtain a satisfactory CTFLP and prevents some crucial conflicts, thus, promoting construction operations and making a significant contribution to the practice of construction projects.
\end{abstract}

Keywords: CTFLP; TRP; large-scale construction projects; MINBLPM; HGABPSO 


\subsection{Introduction and research aim}

Construction, design, maintenance, management and life-cycle performance of large-scale construction projects, such as bridges, dams and power plants, are becoming more and more important (Yeo et al. 2013). The construction temporary facilities layout planning (CTFLP) is significantly complex in the process of construction and appropriate CTFLP has a positive effect on the overall safety and effectiveness (El-Rayes and Khalafallah 2005). The CTFLP refers to find appropriate locations for construction temporary facilities (CTFs) (such as water supply stations, storage depots, integrated warehouses, offices, labor residences and construction substations) on the site while optimizing the respective objectives in different construction projects (Xu and Song 2014). Cheng and O'Connor (1996) indicated that the CTFLP has interactive conflicts with many other pre-planning tasks, such as the transport routes planning (TRP), the project schedule planning, the procurement tasks planning and the workforce planning. In most large-scale construction projects, some pre-planning tasks (such as the CTFLP) are carried out by the general contractor and some tasks (such as the TRP) are conducted by the subcontractors. The general contractor and the subcontractors interact with each other for their respective task optimizations and subsequent conflicts become unavoidable (Cheng and O'Connor 1996). In this context, a conflict is defined as any action or circumstance resulting from incompatible or opposing needs (Peña-Mora et al. 2003). If the conflicts are not resolved, the adversarial relationships will jeopardize potential or ongoing collaborative construction operations (Elazouni and Metwally 2000; Humphreys et al. 2003; Shafaat et al. 2014; Arditi and Chotibhongs 2005). Moreover, the Ministry of Housing and Urban-Rural Development has reported serious accidents in China since the conflicts between the general contractor and the subcontractors were not resolved. Accordingly, great economic loss, construction delays, injuries and fatalities to workers were resulted from inappropriate CTFLP. Those reasons motivate the authors to determine the CTFLP based on resolving the crucial conflicts between the general contractor and the subcontractors.

Significant research has demonstrated the importance of efficient CTFLP and some methods were proposed to obtain suitable CTFLP on construction sites (Zouein and Tommelein 1999; Zouein et al. 2002; Elbeltagi et al. 2004; El-Rayes and Khalafallah 2005; El-Rayes and Said 2009; Xu and Song 2014). However, to the authors' knowledge, little research has been conducted to resolve the conflicts in the process of the CTFLP. Therefore, this study attempts to provide project managers with a reference for appropriate CTFLP based on the conflicts resolution between the CTFLP and other preplanning tasks. In particular, a novel method is proposed to conduct the CTFLP based on resolving the crucial conflicts between the CTFLP and the TRP. During the process of the CTFLP, to ensure sound and continuous construction, the transport of materials, workforces, equipment from one CTF to another CTF depends on the TRP (Mohemmed et al. 2008), thus, the CTFLP and the TRP are interrelated and mutually affected (Cheng and O'Connor 1996). Much research was also conducted to plan transport routes due to its importance for site planners in complex large-scale construction projects (Gipps et al. 2001; Soltani et al. 2002; Nuortio et al. 2006; Mohemmed et al. 2008). The studies that the TRP has close relationship to the CTF locations. Thus, the CTFLP and the TRP are considered simultaneously here. Generally, the construction sites for dams or power plants often take place in deep valleys, steep bank slopes, and exposed bedrock, which increases the difficulty of determining the CTFLP and the TRP simultaneously. Figure 1 shows a practical difficulty for deciding on the CTFLP and the TRP on a construction site. Based on the previous statements, the CTFLP and the TRP can be modeled as a bi-level hierarchical problem. The detailed motivations for considering the conflicts resolution between the CTFLP and the TRP are demonstrated in Section 2.1 .

This study contributes to the CTFLP studies by resolving the conflicts between the CTFLP and the TRP. Specifically, it proposes a new two procedures-based methodology to obtain suitable CTFLP based on the conflicts resolution between the CTFLP and the TRP. Procedure I establishes a mixed integer nonlinear bi-level 
programming model (MINBLPM) for suitable CTFLP based on the conflicts resolution between the CTFLP and the TRP. Since bi-level programming problems are NP-hard problems, the hybrid of Genetic Algorithm (GA)-binary Particle Swarm Optimization (PSO) (HGABPSO) is proposed in Procedure II for satisfactory solutions. In procedure I, when establishing a MINBLPM to resolve the conflicts (this will be clearly described in Section 2), many uncertain parameters are confronted since both the CTFLP and the TRP are pre-planning tasks that need many estimations. Thus, fuzzy random variables (FRVs) proposed by Kwakernaak (1978) are employed in the MINBLPM. FRVs have been widely used and their applicabilities in dealing with uncertain parameters are proved (Moller and Reuter 2007; Xu and Liu 2008; Dabbous 2010; Xu et al. 2013b). In Procedure II, a novel HGABPSO based on the hybrid of binary particle swarm optimization (BPSO) and the crossover and mutation operators from genetic algorithm (GA) is proposed to solve the MINBLPM for appropriate CTFLP. It is worth noting that bi-level decision makers depend partly on a degree of interaction or cooperation, and they only need to obtain satisfactory solutions for references. Compared to optimal solutions, satisfactory solutions need to achieve solutions with better objectives than the predetermined levels. In past decades, there are already much research integrating PSO and GA based on their respective merits (Du et al. 2006; Fan et al. 2006; Fan and Zahara 2007; Kao and Zahara 2007; Kuo and Han 2011). This study incorporates the BPSO with the mutation and crossover operators from GA to solve the proposed MINBLPM in Procedure I.

The remainder of this study is organized as follows: Section 2 explains the significance of conflicts resolution and identifies the conflicts in an uncertain environment. The new methodology based on two procedures is proposed in Section 3. To verify the effectiveness and efficacy of the proposed methodology, a dam construction project is used as a test example in Section 4, along with which some discussions are made. By using the proposed methodology to solve the practical problem, some useful suggestions are provided in Section 5 for obtaining better CTFLP by considering other conflicts resolution. Section 6 concludes the study with some contributions and recommendations for future research.

\subsection{Research problem statement}

The CTFLP becomes rather complex when the conflicts resolution between the CTFLP and the TRP is crucial. So a comprehensive investigation is needed to demonstrate the motivations of considering conflicts resolution, to identify potential conflicts and to identify the importance of uncertain parameters first.

\subsection{Motivations for conflicts resolution between the CTFLP and the TRP}

In most large-scale construction projects (e.g. dams, power plants), many conflicts arise between the CTFLP and the TRP (Cheng and O'Connor 1996). Resolving these conflicts is crucial for satisfactory CTFLP and the motivations are summarized as follows: First, much research has indicated that specialty subcontractors were quite common and important in construction projects and resolving the conflicts between the general contractor and each specialty subcontractor is critical for their decisions (Elazouni and Metwally 2000; Arditi and Chotibhongs 2005; Shafaat et al. 2014). Second, many cooperations between the general contractor and the subcontractor in large-scale construction projects failed since the conflicts between the CTFLP and the TRP were not resolved. As a consequence, the general contractor had to terminate the contracts, and the whole project was delayed or the total costs increased. What's worse, inappropriate CTFLP often resulted in many injuries and fatalities. This is the most critical reason for resolving the conflicts between the CTFLP and the TRP as many as possible when deciding on the CTFLP. Third, large-scale construction projects are established in far-away mountainous areas, accordingly, potential CTF locations and transport routes need to be established by the project itself based on real-world investigations and surveys. The CTFLP and the TRP are conducted by the different general contractor and subcontractor. The more CTFs and transport routes they need, the more incompatible actions are resulted. Consequently, it is vital to resolve the potential conflicts between the CTFLP and the TRP in advance for satisfactory CTFLP. 


\subsection{Conflicts identification between the CTFLP and the TRP}

The conflicts resolution between the CTFLP and the TRP is vital for appropriate CTFLP, and identifying important conflicts is the primary step. Generally, the general contractor locates different CTFs in suitable locations based on the conditions and the total interactive costs between all facilities (CTFs and fixed facilities included). If there are interactive operations between any two CTFs, there should be direct or indirect routes. The decisions are delivered to the subcontractor, who will decide on the TRP whiling minimizing the total construction and maintenance costs as well as minimizing the total risks. The subcontractor will also present its solutions to the general contractor. In this way, both the general contractor and the subcontractor attempt to optimize their objectives based on their respective requirements and the other's actions and reactions (Osman et al. 2004). Consequently, many conflicts (incompatible actions) occurred and interactions are needed before updating their respective requirements to reach a satisfactory solution. Figure 2 identifies important conflicts between the CTFLP and the TRP with uncertainty and all conflicts are as below.

To begin with, conflicts arise in the general contractor and the subcontractor's respective objectives. In real-world situations, the general contractor and the subcontractors always have conflicts in the payment (Hinze and Tracey 1994; Arditi and Chotibhongs 2005). When determining suitable CTFLP, the general contractor proposes the total costs minimization as its top priority. The subcontractor is planning suitable transport routes to minimize its construction and maintenance costs, thus, maximizing their profits. Besides, the risks along with the construction and maintenance of the transport routes are also important for the subcontractor. When conducting the CTFLP, the general contractor attempts to locate some specific CTFs in certain potential feasible locations (PFLs), which cost a lot to construct routes between those locations, thus, increasing the subcontractor's total costs or increasing the construction and maintenance risks. On the contrary, planning and constructing routes with low risks or low total costs between certain PFLs may increase the interactive costs between some CTFs, thus, increasing the general contractor's total costs. Conflicts arise in this process, and the contractor-subcontractor will fail if any objectives cannot reach their requirements. Therefore, resolving these conflicts is crucial for the CTFLP and the TRP.

Conflicts also arise in the general contractor and the subcontractor's decision variables and constraints. For the general contractor, it aims to locate CTFs in suitable PFLs. When it positions the same CTF in different locations, the subcontractor may decide different transport routes through it. For instance, when it locates CTF 1 at the PFL 5, the subcontractor will not plan transport routes from PFL 5 and PFL 7 directly. Instead, it will construct routes from PFL 5 to PFL 8, and then to PFL 7. Similarly, the subcontractor plans transport routes between PFLs and different transport routes will result in different plans for the general contractor's transportation of commodities. For example, if it constructs route between CTF 1 at PFL 5 and CTF 5 at PFL 7, the general contractor will transport commodity 2 between them. If not, the general contractor will choose other transport routes. Thus, conflicts arise in the decision makers' decision variables. At the same time, one decision maker will face constraints from another decision maker when optimizing their behaviors. For example, the general contractor can use specific route between some PFLs under the premises that the subcontractor constructs this route. Therefore, resolving these incompatible actions is vital for appropriate CTFLP.

\subsection{Uncertain parameters intensifying the conflicts}

The resolution of the conflicts is vital for appropriate CTFLP, however, both the CTFLP and the TRP are conducted before the construction and operation processes. Under these circumstances, many important parameters are estimated by experienced experts when conducting the practical investigations and surveys. Accordingly, uncertainties arise and intensify the conflicts between the CTFLP and the TRP. FRVs are applied in the study to represent uncertain parameters. For example, to collect data about the unit cost for transporting materials $\left(c_{i j}\right)$ between CTF $i$ and CTF $j$, investigations and discussions are made with several experienced experts (i.e., $q=1,2, \ldots, Q$, where $q$ is decision 
maker's index). Unfortunately, they describe $c_{i j}$ in linguistic terms as intervals (i.e., $\left(l_{q}, r_{q}\right)$ ) with most possible values (i.e., $m_{q}$ ) instead of providing determined numbers. For instance, "The $c_{23}$ is between 2.145 yuan $/(\mathrm{t} \cdot \mathrm{km})$ and 2.337 yuan $/(\mathrm{t} \cdot \mathrm{km})$, and the most possible value is $2.230 \mathrm{yuan} /(\mathrm{t} \cdot \mathrm{km})$ ". In addition, objective factors, such as weather fluctuations, economic crises, have great impacts on those experts' estimations. Then, the minimum of all $l_{q}$ is selected as the left border (i.e., $c_{l}$ ), the maximal of all $r_{q}$ is selected as the right border (i.e., $c_{r}$ ), and the most possible values $m_{q}$ for $c_{i j}$ can be described by a stochastic distribution (Xu et al. 2013b). Based on the maximum likelihood method and a chi-square goodness-of-fit test (Xu et al. 2013b), $m_{q}$ is a random variable (i.e., $c_{m}$ ) and approximately follows a normal distribution (i.e., ${ }_{m} \sim N\left(\mu, \delta^{2}\right)$ ). Thus, $c_{i j}$ can be expressed as triangular fuzzy random parameters $\left(c_{l}, c_{m}, c_{r}\right)$, where $c_{m} \sim N\left(\mu, \delta^{2}\right)$. Similarly, parameters that are with the same situations to $c_{i j}$ are also represented as FRVs. Figure 3 presents the whole process of employing FRVs.

The applications of the FRVs make the CTFLP and the TRP more practical but more difficult to solve. FRVs intensify the conflicts between the two decision makers to some extent. For example, when the general contractor's estimations on the interactive costs between CTFs in certain locations are uncertain, it is harder for the subcontractor to plan transport routes based on the selected locations. On the contrary, if the subcontractor feel difficult to estimate the total construction and maintenance costs as well as the risks along transport routes, then it is harder for the general contractor to plan transport routes for different commodities. Figure 3 also shows how uncertainties intensify the conflicts between the general contractor and the subcontractor. Thus, uncertain parameters indirectly intensify the conflicts between the two decision makers and resolving these uncertainties is vital for resolving the conflicts and obtaining satisfactory CTFLP.

\subsection{Methodology}

To resolve the conflicts for the CTFLP, a new methodology based on a MINBLPM and the HGAPSO is proposed.

\subsection{Procedure I: the MINBLPM for the conflicts resolution based CTFLP}

The CTFLP and the TRP are important and interacted in practical large-scale construction projects. Resolving the conflicts is vital for obtaining satisfactory CTFLP, thus, a MINBLPM is established based on their respective objectives and mutual interactions. Assumptions are presented first: (1) PFLs are identified in advance based on practical investigations and surveys. (2) There are more identified PFLs than the required locations for CTFs. (3) Constructing routes between two fixed facilities is also considered.

\subsubsection{Total costs minimization for the CTFLP}

The CTFLP is important for construction operations and the total costs minimization is always the most important objective for the general contractor when locating CTFs in suitable PFLs (Elbeltagi et al. 2004). Much research attempted to minimize the total interactive costs between CTFs on the construction site for buildings, stadiums etc. (Elbeltagi et al. 2004; El-Rayes and Khalafallah 2005; El-Rayes and Said 2009; Xu and Song 2014; 
Sadeghpour and Andayesh2015). However, when constructing large-scale construction projects (e.g. dams, power plants) in mountainous areas, determining appropriate CTFLP becomes much more difficult due to the natural, topographical, geographical and conditional restrictions. In this study, PFLs for CTFs are predetermined based on several months' investigations of real-world situations. Thus, evaluating the total costs relating to suitable CTFLP becomes more complicated. Positioning different CTFs in different PFLs will result in different costs due to the CTF characteristics and the topographical, geographical or transportation differences of PFLs. Therefore, the setup and the close-up costs for CTFs in different PFLs constitute the first part relating to the CTFLP total costs, which are modelled as $\tilde{\bar{c}_{i m}} x_{i m}$. There are many on-site material and equipment interactions between CTFs once they are established in PFLs. The different CTFLP result in different interactive costs and the interactive costs have been researched in many studies. The interactive costs of positioning a CTF on a PFL neighboring another CTF in another PFL are modelled as $\sum_{i, j=1}^{J} \sum_{m, n=1}^{M} \tilde{\bar{Q}}_{i j} \tilde{\bar{c}}_{i j} d_{m n} x_{i m} x_{j n} y_{m n}$ in this study, in which $d_{m n}$ is the actual center-to-center distance of all facilities based on practical routes and it is able to reflect the locations change of all storage and temporary facilities change in accordance with the process. Besides, in large-scale construction projects (e.g. power plants), CTFs are established to facilitate the construction operations for fixed facilities (e.g. dams, substations). There are interactive costs between CTFs and fixed facilities and the different CTFLP result in different interactive costs. Thus, the interactive costs between CTFs and fixed facilities are modelled as $\sum_{i=1}^{J} \sum_{m=1}^{M} \sum_{f=1}^{F} \tilde{\bar{Q}}_{i f} \tilde{\bar{c}}_{i f} d_{m f} x_{i m} y_{m f}$.

Generally speaking, the total costs are mainly composed of the setup and close-up costs for CTFs in different PFLs, the interactive on-site materials and equipment transporting costs between CTFs and the interactive transporting costs between CTFs and fixed facilities. Therefore, the total costs for the CTFLP are modelled as $\tilde{\bar{c}}_{i m} x_{i m}+\sum_{i, j=1}^{J} \sum_{m, n=1}^{M} \tilde{\bar{Q}}_{i j} \tilde{\bar{c}}_{i j} d_{m n} x_{i m} x_{j n} y_{m n}+\sum_{i=1}^{J} \sum_{m=1}^{M} \sum_{f=1}^{F} \tilde{\bar{Q}}_{i f} \tilde{\bar{c}}_{i f} d_{m f} x_{i m} y_{m f}$.

Since there are FRVs in the objective function, an expected value operator is applied to convert all FRVs into deterministic variables if a project tends to obtain an average level of these collected data (Xu and Zhou 2009). This study applies the expected value based on the practical requirement of a project. For example, $\tilde{\bar{c}}_{i m}$ can be converted into $\tilde{\bar{c}_{i m}}=\tilde{c}_{i m}\{r, q\}=\left(\left[c_{i m}\right]_{L}, \underline{c}_{i m}, \bar{c}_{i m},\left[c_{i m}\right]_{R}\right)$, and $E\left(\tilde{c}_{i m}\right)=\frac{1}{2}\left[\left(c_{c_{i m}}-\int_{\left[c_{i m} l_{L}\right.}^{c_{c_{m}}} f(x) d x\right)+\left(\bar{c}_{i m}-\int_{\bar{c}_{i m}}^{\left[c_{i m}\right]_{R}} g(x) d x\right)\right]$. Noted that $f(x)$ is an increasing function and $g(x)$ is a decreasing function. Similarly, the expected values for $\tilde{\bar{c}}_{i j}, \tilde{\bar{c}_{i f}}, \tilde{\bar{Q}_{i j}}, \tilde{\bar{Q}}_{i f}, \tilde{\bar{c}}_{m n}, \tilde{\bar{c}}_{m f}, \tilde{\bar{r}}_{m n}$ and $\tilde{\bar{r}}_{m f}$ can be converted into $E\left(\tilde{c}_{i j}\right), E\left(\tilde{c}_{i f}\right), E\left(\tilde{Q}_{i j}\right), E\left(\tilde{Q}_{i f}\right), E\left(\tilde{c}_{m n}\right), E\left(\tilde{c}_{m f}\right)$, $E\left(\tilde{r}_{m n}\right)$ and $E\left(\tilde{r}_{m f}\right)$ respectively. Thus, the total costs function can be converted as:

$$
\min \operatorname{Cost}_{L}(x, y)=E\left(\tilde{c}_{i m}\right) x_{i m}+\sum_{i, j=1}^{J} \sum_{m, n=1}^{M} E\left(\tilde{Q}_{i j}\right) E\left(\tilde{c}_{i j}\right) d_{m n} x_{i m} x_{j n} y_{m n}+\sum_{i=1}^{J} \sum_{m=1}^{M} \sum_{f=1}^{F} E\left(\tilde{Q}_{i f}\right) E\left(\tilde{c}_{i f}\right) d_{m f} x_{i m} y_{m f} .
$$

For the objective function in eq. [1], $y_{m n}$ and $y_{m f}$ are solved in the lower level model. In order to obtain suitable CTFLP for the general contractor, all CTFs have to be positioned in the construction site and the PFL areas have to be equal to or greater than the CTF areas. This can be modelled as:

$$
S_{i} x_{i m} \leq D_{m}
$$

In practical projects, large machines also impact the locations of the CTFs. The locations for large machines are commonly identified by the project itself based on a series of qualitative and quantitative analyses. Accordingly, the locations for the CTFs accommodating large machines are determined. For example, the concrete batching unit is a large machine that is used to produce concrete for dam construction, and its location is decided in advance. Therefore, 
the location for the concrete shop is predetermined when resolving the problem of layout planning. This can be modelled as:

$$
x_{i m^{\prime}}=1, \forall i^{\prime} \in \Xi=\left\{1,2, \ldots, I^{\prime}\right\},
$$

where $i^{\prime} \in \Xi=\left\{1,2, \ldots, I^{\prime}\right\}$, denoting the CTFs with predetermined PFLs.

One CTF should be allocated to only one PFL, thus,

[4] $\quad \sum_{m=1}^{M} x_{i m}=1, \forall i \in \Omega=\{1,2, \ldots, J\}$.

One PFL can accommodate only one CTF and $\mathrm{x}_{\mathrm{im}}$ has to be $0-1$ variables, thus,

[5] $\quad \sum_{i=1}^{J} x_{i m}=1, x_{i m}=\{0,1\}, \forall m^{\prime} \in \Phi=\left\{1,2, \ldots, M^{\prime}\right\}$.

\subsubsection{Total costs minimization and total risks minimization for the TRP}

The subcontractor deals with the problem of planning on-site materials and equipment transport routes for the general contractor. In other words, they need to decide whether to construct routes between any two facilities (CTFs and fixed facilities included) according to the CTFLP. Mathematically, the subcontractor solves the problems of planning $y_{m n}$ and $y_{m f}$ after the PFLs $\mathrm{m}$ and $\mathrm{n}$ are selected to locate CTFs $i$ and $j$. The TRP problems usually attempt to transport materials and equipment from origins to destinations at their minimal costs. The subcontractor plans transport routes based on the CTFLP $\left(x_{i m}\right.$ and $\left.x_{j n}\right)$, which represents that the general contractor has great influences on the subcontractor's decisions. The subcontractor selects transport routes to construct and maintain based on the topographical and geographical conditions between PFLs and fixed facilities. Evaluating the total costs is quite important for the subcontractor to design transport routes between PFLs. The construction and maintenance costs between CTFs are modelled as $\sum_{i, j=1}^{J} \sum_{m, n=1}^{M} E\left(\tilde{c}_{m n}\right) d_{m n} x_{i m} x_{j n} y_{m n}$. When calculating the distances between facilities (CTFs and fixed facilities included), the locations of all storage and temporary facilities change in accordance with the process

Besides, there are interactive activities between CTFs (PFLs) and fixed facilities, thus, it is necessary to construct some transport routes to transport materials and equipment in large-scale construction projects. The costs of construction routes between CTFs and fixed facilities are modelled as $\sum_{i=1}^{J} \sum_{f=1}^{F} E\left(\tilde{c}_{m f}\right) d_{m f} x_{i m} y_{m f}$. Therefore, the total costs for the subcontractor when designing transport routes are modelled as:

$$
\min \operatorname{Cost}_{F}(x, y)=\sum_{i, j=1}^{J} \sum_{m, n=1}^{M} E\left(\tilde{c}_{m n}\right) d_{m n} x_{i m} x_{j n} y_{m n}+\sum_{i=1}^{J} \sum_{f=1}^{F} E\left(\tilde{c}_{m f}\right) d_{m f} x_{i m} y_{m f} .
$$

However, many accident take places when constructing and maintaining transport routes on the construction site and the total costs minimization is not the subcontractor's only objective. Many emergency response teams, such as fire-fighting, hospital, ambulance and police services, are employed to decrease the accident rates (Hamouda et al. 2004; Berman et al. 2007; Zografos and Androutsopoulos 2008; Xu et al. 2013a). The total risks relating to the TRP are the sum of the risks on each route, which depends on whether these routes are covered by any emergency response teams. Hamouda et al. (2004) and Xu et al. (2013a) developed the risk assessment models considering emergency response teams to decrease the risks. This study develops the risk assessment model in Xu et al. (2013a) to describe the risks associated with the construction and maintenance of transport routes in large-scale construction projects. The risks on the routes between CTFs can be modelled as $\sum_{i, j=1}^{J} \sum_{m, n=1}^{M} E\left(\tilde{r}_{m n}\right) d_{m n} x_{i m} x_{j n} y_{m n}$ and the risks on the routes 
between CTFs and fixed facilities can be modelled as $\sum_{i=1}^{J} \sum_{f=1}^{F} E\left(\tilde{r}_{m f}\right) d_{m f} x_{i m} y_{m f}$. When the routes between CTFs and fixed facilities are covered by emergency response team, the risks on those routes will be decreased. $a_{1}\left(D_{\max }-D_{m n}^{t}\right) h_{m n}^{t}$ describes the percentage of reduced risk on the routes between CTFs and $a_{2}\left(D_{\max }-D_{m f}^{t}\right) h_{m f}^{t}$ describes that between CTFs and fixed facilities.

Note that the parameters $a_{1}$ and $a_{2}$ can be estimated based on the consequences of the accidents and the effective responses of the emergency response teams, which is demonstrated in Figure 4. The responses of the emergency teams are firstly evaluated and the consequences of accidents are classified as $a_{1}^{1}, a_{1}^{2}, \ldots, a_{1}^{P}$ and $a_{2}^{1}, a_{2}^{2}, \ldots, a_{2}^{Q}$ based on past experiences. Correspondingly, the weights $\left(w_{1}^{1}, w_{1}^{2}, \ldots, w_{1}^{P}\right.$ and $\left.w_{2}^{1}, w_{2}^{2}, \ldots, w_{2}^{O}\right)$ for different consequences are determined. According to various consequences, the most possible decrease values for the consequences are estimated then and the weighted sum of these values are taken as the final value for $a_{1}\left(a_{1}=a_{1}^{1} w_{1}^{1}+a_{1}^{2} w_{1}^{2}+\ldots+a_{1}^{P} w_{1}^{P}\right)$ and $a_{2}\left(a_{2}=a_{2}^{1} w_{2}^{1}+a_{2}^{2} w_{2}^{2}+\ldots+a_{2}^{Q} w_{2}^{Q}\right)$. In real-world situations, it is difficult to obtain exact values for $a_{1}$ and $a_{2}$, thus, effective sensitivity analysis can be applied for the subcontractors' practical management.

Therefore, the total risks when constructing and maintaining the transport routes can be modelled as:

$$
\begin{aligned}
& \min \operatorname{RISK}_{F}(x, y)=\sum_{i, j=1}^{J} \sum_{m, n=1}^{M} E\left(\tilde{r}_{m n}\right) d_{m n} x_{i m} x_{j n} y_{m n}\left\{1-\alpha_{1}\left(D_{\max }-D_{m n}^{t}\right) h_{m n}^{t}\right\} \\
& +\sum_{i=1}^{J} \sum_{f=1}^{F} E\left(\tilde{r}_{m f}\right) d_{m f} x_{i m} y_{m f}\left\{1-\alpha_{2}\left(D_{\max }-D_{m f}^{t}\right) h_{m f}^{t}\right\} .
\end{aligned}
$$

Based on practical situations, the routes cannot be constructed between some CTFs, thus,

$$
y_{m_{1} n_{1}}=0, m_{1} \in \Phi, n_{1} \in \Phi .
$$

Only the nearest emergency response team is used to decrease the negative consequences when accidents happen, which can be modelled as:

$$
\sum_{t \in \Lambda} h_{m n}^{t} \leq 1, m, n \in \Phi
$$

The maximum travel distance for any emergency response team cannot exceed the travelling threshold $\mathrm{D}_{\max }$, which can be modelled as:

$$
D_{m n}^{t} \leq h_{m n}^{t} D_{\max }, m, n \in \Phi .
$$

The variables $y_{m n}$ and $y_{m f}$ have to be $0-1$ variables:

$$
y_{m n}=y_{n m}, y_{m f}=y_{f n}, y_{m n} \in\{0,1\}, y_{m f} \in\{0,1\}
$$

\subsubsection{Global optimization model for appropriate CTFLP}

There exist interactive influences between the general contractor and the subcontractor when the former is determining the CTFLP and the latter is planning transport routes for materials and equipment on the construction site. The general contractor's decisions $\left(x_{i m}\right.$ and $\left.x_{j n}\right)$ affect the subcontractor's decisions $\left(y_{m n}\right.$ and $\left.y_{m f}\right)$. Similarly, the subcontractor's decisions $\left(y_{m n}\right.$ and $\left.y_{m f}\right)$ affect the general contractor's decisions $\left(x_{i m}\right.$ and $\left.x_{j n}\right)$. Thus, both decision makers attempt to obtain optimal solutions based on their respective objectives and another decision maker's 
interactions. Conflicts arise when the general contractor's optimal decisions are incompatible with the subcontractor's optimal decisions and resolving the conflicts is vital for appropriate CTFLP. Therefore, a MINBLPM is established, in which both the general contractor and the subcontractor attempt to obtain their respective satisfactory solutions. In real-world situations, the general contractor aims to locate CTFs in suitable PFLs $\left(x_{i m}\right.$ and $\left.x_{j n}\right)$ based on the interactive relationships between facilities (CTFs and fixed facilities included). Meanwhile, the transporting routes for different commodities between facilities can be obtained. Thus, the total interactive costs for the general contractor are composed of the interactive costs between facilities (CTFs and fixed facilities included), which are shown in eq. [1]. FRVs are employed in eq. [1] to reflect the uncertainties when estimating the total costs for the general contractor and eqs. [2-5] are proposed to reflect the practical constraints.

The CTFLP of the general contractor is delivered to the subcontractor, who will plan transport routes $\left(y_{m n}\right.$ and $y_{m f}$ ) for the general contractor. The conflicts occur when the subcontractor is not satisfied with the general contractor's decisions or the general contractor is not satisfied with the subcontractor's decisions. In this study, the general contractor affects the subcontractor's by locating CTFs in PFLs and using the subcontractor's planned routes for transporting. Similarly, the subcontractor affects the general contractor's decisions by constructing necessary routes with total costs minimization and total risks minimization. The objectives for the TRP are obtained in eqs. [6-7]. eqs. [8-11] are employed to reflect the practical constraints when minimizing its total costs and risks. As a consequence, both the general contractor and the subcontractor will interact for suitable CTFLP based on their respective requirements and another's interactions and the complete model is formulated in eq. [12]. It is noted, under some circumstances, the general model may not be applied directly into all large-scale project construction due to the different construction process and practical situations. Thus, some issues related to construction process are needed to be considered simultaneously for resolving the CTFLP and some modifications (such as adding or changing constraints) are encouraged in practical applications.

$$
\begin{aligned}
& \int \min \operatorname{Cost}_{L}(x, y)=E\left(\tilde{c}_{i m}\right) x_{i m}+\sum_{i, j=1}^{J} \sum_{m, n=1}^{M} E\left(\tilde{Q}_{i j}\right) E\left(\tilde{c}_{i j}\right) d_{m n} x_{i m} x_{j n} y_{m n}+\sum_{i=1}^{J} \sum_{m=1}^{M} \sum_{f=1}^{F} E\left(\tilde{Q}_{i f}\right) E\left(\tilde{c}_{i f}\right) d_{m f} x_{i m} y_{m f}, \\
& S_{i} x_{i m} \leq D_{m} \text {, } \\
& x_{i m^{\prime}}=1, \forall i^{\prime} \in \Xi=\left\{1,2, \ldots, I^{\prime}\right\}, \\
& \sum_{m=1}^{M} x_{i m}=1, \forall i \in \Omega=\{1,2, \ldots, J\} \text {, } \\
& \sum_{i=1}^{J} x_{i m}=1, x_{i m}=\{0,1\}, \forall m^{\prime} \in \Phi=\left\{1,2, \ldots, M^{\prime}\right\} \text {, } \\
& \left\{\begin{array}{l}
\min \operatorname{Cost}_{F}(x, y)=\sum_{i, j=1}^{J} \sum_{m, n=1}^{M} E\left(\tilde{c}_{m n}\right) d_{m n} x_{i m} x_{j n} y_{m n}+\sum_{i=1}^{J} \sum_{f=1}^{F} E\left(\tilde{c}_{m f}\right) d_{m f} x_{i m} y_{m f}, \\
\left.\min \operatorname{RISK}_{F}(x, y)=\sum^{J} \sum^{M} E\left(\tilde{r}_{i}\right) d_{m} x_{m x} x_{n} y_{m i} \alpha_{1}\left(D_{m a}-D^{t}\right) h^{t}\right\}
\end{array}\right. \\
& \left\{\min \operatorname{RISK}_{F}(x, y)=\sum_{i, j=1}^{J} \sum_{m, n=1}^{M} E\left(\tilde{r}_{m n}\right) d_{m n} x_{i m} x_{j n} y_{m n}\left\{1-\alpha_{1}\left(D_{\max }-D_{m n}^{t}\right) h_{m n}^{t}\right\}\right. \\
& +\sum_{i=1}^{J} \sum_{f=1}^{F} E\left(\tilde{r}_{m f}\right) d_{m f} x_{i m} y_{m f}\left\{1-\alpha_{2}\left(D_{\max }-D_{m f}^{t}\right) h_{m f}^{t}\right\}, \\
& \text { s.t. }\left\{\begin{array}{l}
y_{m_{1} n_{1}}=0, m_{1} \in \Phi, n_{1} \in \Phi, \\
\sum_{t \in \Lambda} h_{m n}^{t} \leq 1, m, n \in \Phi, \\
D_{m n}^{t} \leq h_{m n}^{t} D_{\max }, m, n \in \Phi, \\
y_{m n}=y_{n m}, y_{m f}=y_{f m}, y_{m n} \in\{0,1\}, y_{m f} \in\{0,1\} .
\end{array}\right.
\end{aligned}
$$

\subsection{Procedure II: solving the proposed eq. [12] based on HGABPSO for appropriate CTFLP}

Bi-level programming problems (BLPPs) have a wide variety of applications, such as supply chain problem (Ma et al. 2014), network design problem (Farvaresh and Sepehri 2013), and facility layout problem (Miller et al. 1992). In Procedure I, establishing bi-level programming models is effective in handling the conflicts between the general contractor and the subcontractors. However, solving the model in eq. [12] is a complex challenge. Even for the linear BLPP, the simplest one among the BLPP family, where all of the functions are linear, Jeroslow (1985) and Bard (1991) 
have shown that it is strongly Nondeterministic Polynomial-time hard (NP-hard). Therefore, as a strong NP-hard problem, the proposed MINBLPMs in Procedure I is a more complex and challenging problem. Over the decades, there already have been some methods for solving BLPPs, including methods based on vertex enumeration and meta-heuristics. However, much research focuses on solving linear BLPPs and only a few procedures (e.g., Edmunds and Bard 1992; Al-Khayyal et al. 1992; Jan and Chern 1994; Vicente et al. 1994; Amouzegar 1999; Gümü s and Floudas 2001) have tried to find a global minimum for nonlinear BLPPs, in which genetic algorithm (GA) (Sakawa and Shibano 1997; Sakawa 2000; Yin 2000; Oduguwa and Roy 2002; Wang et al. 2005; Li and Wang 2008) and particle swarm optimization (PSO) (Pei et al. 2006; Kasemset and Kachitvichyanukul 2012) are widely used. Due to the respective merits of each method in searching solutions, there already have been much research integrating GA and PSO (Du et al. 2006; Fan et al. 2006; Fan and Zahara 2007; Kao and Zahara 2007; Kuo and Han 2011). Eberhart and Shi (1998) suggested some ways to enhance GA and PSO's performance by incorporating merits from one into the other. It can effectively integrate the characteristic of global search in GA and the capability of local search in PSO to avoid converging ahead of time and to raise the accuracy of problem solving. Some scholars have indicated that the integrated PSO and GA demonstrated superiority over the PSO or the GA in terms of solution quality and convergence rates in their respective problems (Kao and Zahara 2007; Kuo and Han 2011). Thus, a novel HGABPSO based on the hybrid of the binary PSO (BPSO) and the crossover and mutation operators from GA is proposed in Procedure II to solve eq. [12] for satisfactory solutions.

\subsubsection{Overview of GA}

The origin of GAs can be dated back to the 1960s by Holland (1975) and Goldberg (1989). The GAs are techniques that solve problems by searching global optima stochastically based on the fitness of different solutions. At each generation of GA, a new set of solutions will be reproduced based on selection, mutation and crossover operations (Vasconcelos et al. 2001). In past decades, GAs have been applied in many fields, such as multiobjective optimization (Horn et al. 1994), job-shop scheduling (Chang et al. 2014) and supply system (Neungmatcha et al. 2012). In specific problems, individual chromosomes are encoded and decoded as solutions, and a population of these individuals is defined along with a required population size (Pop. Size), representing a solution space for those problems. Firstly, GA selects a set of chromosomes randomly to be the initial solutions for the problem. Then, it evaluates the individual to obtain corresponding fitness of the solution based on some objective functions. The best solution until now is often memorized before the stop criteria are met, which means that the elitist strategy is often used. If the stop criteria are not met, the Pop. Size individuals will be selected to obtain a new set of chromosomes based on selection, mutation and crossover operations with some probabilities. Mutation and crossover operations are quite important in GA since mutation tends to have less impact near the beginning of a run and more near the end, and oppositely, crossover has significant effects on the beginning of the run and less on the end (Eberhart and Shi 1998). Note that the expected fitness over the new set of chromosomes (solutions) is better than that of the previous set of chromosomes (solutions) and the best solution will be memorized. The whole process is repeated until the termination criteria are met, and the best chromosome of the last generation is the final solution for the specific problem. Since all decision variables in eq. [12] are 0 - 1 variables, the revised "partially matched crossover (PMX)" proposed by Sakawa and Nishizaki (2009) is used as a crossover operator and the "swap mutation" is used as a mutation operator in this study.

\subsubsection{Overview of basic PSO and BPSO}

PSO is originally proposed and designed by Kennedy and Elberhart (1995). PSO is also an evolutionary computational technique based on swarm intelligence, which is widely used in various fields, including multiobjective 
optimization problems (Hu and Eberhart 2002), economic dispatch (Park et al. 2005). Instead of using genetic operators (selection, mutation and crossover) in GA, each particle (individual) updates its solutions based on its own experience and its neighbors' experience. In specific problems, PSO firstly initiates a set of potential solutions randomly and attempts to find the best solution (particle) based on its present velocity, its previous experience, and its neighbors' experiences. The position and the velocity for the particle are demonstrated in an $n$-dimensional search space as $O_{a}=\left\{o_{a 1}, o_{a 2}, \ldots, o_{a n}\right\}$ and $V_{a}=\left\{v_{a 1}, v_{a 2}, \ldots, v_{a n}\right\}$, respectively. Accordingly, the personal best position of the $a^{\text {th }}$ particle and the global best position of the population can be represented as Pbest $_{a}=\left\{o_{a 1}^{P}, O_{a 2}^{P}, \ldots, O_{a n}^{P}\right\}$ and Gbest $_{a}=\left\{o_{a 1}^{G}, O_{a 2}^{G}, \ldots, O_{a n}^{G}\right\}$. Then, compared to GA, the solutions in PSO are updated based on updating the velocity and position for each particle based on eqs. [13-14].

[13] $\quad V_{a}^{t+1}=w V_{a}^{t}+c_{1}$ Rand $_{1}\left(\right.$ Pbest $\left._{a}^{t}-O_{a}^{t}\right)+c_{2}$ Rand $_{2}\left(\right.$ Gbest $\left.^{t}-O_{a}^{t}\right)$,

[14] $\quad O_{a}^{t+1}=O_{a}^{t}+V_{a}^{t+1}$,

where $V_{a}^{t}$ denotes the velocity of the $a^{\text {th }}$ particle at the $t^{t h}$ iteration, $w$ represents the inertia weight factor, $c_{1}$ and $c_{2}$ are acceleration coefficients for particles, Rand ${ }_{1}$ and $\operatorname{Rand}_{2}$ are random numbers between 0 and 1 , and $O_{a}^{t}$ is the position of the $a^{\text {th }}$ particle at the $t^{\text {th }}$ iteration.

Similarly, the binary PSO (BPSO) was also introduced by Kennedy and Eberhart (1997; 2001), which aimed to operate PSO in binary search spaces, representing that the position vector of a particle in $O_{a}=\left\{o_{a 1}, o_{a 2}, \ldots, o_{a n}\right\}$ are all 0- 1 variables. And the elements of the velocity in $V_{a}=\left\{v_{a 1}, v_{a 2}, \ldots, v_{a n}\right\}$ correspond to the possibilities that the positions of the particle take a value of 1 or 0 . According to Jeong et al. (2010), an intermediate variable $S\left(v_{a b}^{t+1}\right)$ is defined as a sigmoid limiting transformation when applying BPSO. $S\left(v_{a b}^{t+1}\right)$ can be understood as a probability threshold.

$[15] \quad S\left(v_{a b}^{t+1}\right)=\frac{1}{1+\exp \left(-v_{a b}^{t+1}\right)}$.

If a random number $\operatorname{Rand}_{a b}$ is selected from a uniform distribution in $[0,1]$ and it is less than $S\left(v_{a b}^{t+1}\right)$, then the position $\left(o_{a b}^{t+1}\right)$ of the $b^{t h}$ element in $a^{t h}$ particle at the $t+1^{t h}$ iteration is set to 1 . Otherwise, $o_{a b}^{t+1}$ is set to 0 . Thus, the eq. [15] is replaced as eq. [16] when applying BPSO.

$$
\mathbf{o}_{a b}^{t+1}=\left\{\begin{array}{l}
1, \quad \text { if } \text { Rand }_{a b}<S\left(v_{a b}^{t+1}\right), \\
0, \quad \text { otherwise. }
\end{array}\right.
$$

\subsubsection{The overall framework of HGABPSO}

In order to solve eq. [12], which is a complex MINBLPM with $0-1$ decision variables, this section attempts to integrate the BPSO in Section 3.2.2 with mutation and crossover operators from GA to obtain the most satisfactory solutions. The proposed HGABPSO is a co-evolutionary interactive algorithm, which is applied to solve the CTFLP and the TRP iteratively. This iterative process is repeated until the most satisfactory solution is obtained. Notations 
applied in the proposed HGABPSO algorithm are represented in Appendix 2 and the operation process of the HGABPSO in solving the proposed problem is shown in Figure 5.

By programming the proposed HGABPSO in Matlab2007, the problem in eq. [12] can be solved and appropriate CTFLP is able to be obtained.

\subsection{Example application}

To validate the effectiveness and efficiency of the proposed methodology in practice, an example of obtaining the CTFLP for a large-scale dam construction project is applied ${ }^{\dagger}$. The project (Hydropower A) is located in a mountainous area with deep valleys, steep bank slopes in Sichuan Province, China. The project construction is mainly focus on the dam (fixed facility 1 in Figure 6) and public auxiliary infrastructure (fixed facilities 2,3 and 4 in Figure 6) construction. The concrete dam construction is normally the most critical construction process in the hydropower project due to its great influence on a project's cost, duration, quality, and safety performances (Zhong et al. 2014). A dam block is a basic unit for dam construction and the concrete dam construction is a repetitive process as the dam is built by constructing all the dam blocks in a certain sequence. Generally, the concrete dam construction process are composed of the concrete producing issues, the concrete transporting issues, and the concrete pouring issues (Zhong et al. 2014), all of which have a great impact on the problem of layout planning. Therefore, the construction process of each dam block is abstract as a typical load-transport-unload-return cycle involving the transportation of concrete from the load site to a specified dam block, as shown in Figure 6. When determining the CTFLP for a dam construction, some issues related to the construction process are resolved by using the proposed methodology simultaneously. For example, the concrete producing issues are considered in eq. [3] when the project locates the concrete shop (a CTF) at a specific PFL based on the location requirements of a large machine (concrete batching unit); the transporting issues are transformed into the on-site material and equipment interactions among facilities (CTFs and fixed facilities included), as reflected in eq. [1].

In real-world situations, deciding on the CTFLP for this project has many interactive relationships with many other pre-planning tasks, such as the TRP. However, this project presents great difficulties to decide on the CTFLP and the TRP simultaneously due to its geographical and topographical characteristics, which makes it much more difficult to decide on the CTFLP for construction operations. Under these circumstances, the proposed methodology is applied to resolve the conflicts between the CTFLP and the TRP for appropriate CTFLP. The general contractor attempts to decide on the CTFLP and the subcontractor is in charge of the TRP in this project. All related data for the proposed model and method were collected from Hydropower A with several months' investigations and surveys.

\subsection{Case problem presentation}

Hydropower A is located in a bend of the Jinsha River between Sichuan province and Yunnan province, P. R. China. The project began in 2003 and is to generate $5.712 \mathrm{TWh}$ (billion $\mathrm{kWh}$ ) annually when completed in October, 2015. Hydropower A is to be the main power plant for meeting residential and industrial electricity demands from many southwestern regions, such as Sichuan Province, Yunnan Province, Tibetan autonomous region, Guizhou Province and Chongqing in China. However, it is rather difficult and complex to decide on the CTFLP to support the construction operations, such as the dam and the main offices and to plan many pre-planning tasks based on its geography and topography. During the field investigations and surveys, all pre-planning tasks have to be finished before the construction of Hydropower A. The pre-planning tasks mainly include the project schedule planning, the

\footnotetext{
$\dagger$ There are many interpretations of what constitutes a "large dam". The definition offered by the International Commission on Large Dams (ICOLD) is applied in this study (ICOLD, 1998; Scudder, 2005). Large dams are those more than $15 \mathrm{~m}$ in height or having a storage capacity of more than 3 million cubic meters.
} 
procurement tasks planning, the workforce planning, and the TRP between any two facilities (CTFs and fixed facilities included). All general contractor and subcontractors have invited many experienced engineers or experts to research the geography, estimate related data and provide advices for their tasks.

Once the $45 \times 45 \mathrm{~m}^{2}$ construction site and fixed facilities for Hydropower A are decided (note that fixed facilities and PFLs are decided by the project itself based on several months' investigations and surveys), necessary CTFs need to be established to facilitate construction operations and to ensure the overall efficiency of the project. The needed CTFs for accomplishing the whole construction works are provided by experienced experts based on their long-term discussions and communications. In this project, 18 CTFs are needed, such as offices, integrated warehouses, labor residences and substations. Similarly, the PFLs for positioning CTFs are also identified by the same experienced engineers and experts based on long-term investigations and 30 PFLs are identified.

In this project, the TRP is dependent on the CTFLP and the different CTFLP may result in the different TRP. On the contrary, deciding on suitable CTFLP greatly relies on the TRP for transporting commodities between facilities. During the decisions, the general contractor's optimal solutions may be incompatible with the subcontractor's optimal solutions, and vice versa. Thus, both the general contractor and subcontractor are closely interrelated, and interactions are made between each other to obtain a satisfactory solution. That is to say, appropriate CTFLP and TRP have mutual conflicts with each other and resolving the conflicts is beneficial to obtain satisfactory solutions for both the general and the subcontractor. Figure 6 shows the practical situations for deciding on appropriate CTFLP and TRP for Hydropower A when pre-planning their tasks.

\subsection{Data collection for the MINBLPM in Section 3.1}

The proposed MINBLPM in eq. [12] from Section 3.1 is employed to decide on appropriate CTFLP based on resolving important conflicts between the CTFLP and the TRP.

Table 1 shows the name list for 18 CTFs and 30 PFLs identified to locate the predetermined CTFs based on some experienced engineers and experts' investigations and discussions. For the general contractor, it aims to minimize its total costs in eq. [12] when deciding on appropriate CTFLP to facilitate the construction operations. For the subcontractor, it attempts to minimize its total costs and minimize its total risks in eq. [12] when planning transport routes for the general contractor. Related parameters in eq. [12] are collected from Hydropower A and shown in Tables 2-5, in which Table 2 denotes part of the costs for building up, running, maintaining and closing CTFs in PFLs; Table 3 shows the unit interactive cost and exchange volumes between facilities (CTFs and fixed facilities included); Table 4 shows the distances between locations (PFLs and locations of fixed facilities included). It is noted that the locations of all storage and temporary facilities change in accordance with the dam construction process (as shown in Figure 6). Thus, the actual route distance is measured as the center-to-center distances of all facilities based on practical routes; Table 5 shows the unit construction and maintenance cost for transport routes and the unit risk along with constructing and maintaining routes. Since there are many uncertain parameters, 100 experienced experts were invited to discuss and decide values for all FRVs in eq. [12]. The following method in Figure 7 is applied when collecting FRVs for both the CTFLP and the TRP.

\subsection{Data collection and implementation of the HGABPSO in Section 3.2}

After setting values for all parameters in eq. [12], the proposed HGABPSO method is programmed in Matlab2007 to obtain appropriate CTFLP. In the proposed method in Section 3.2, necessary parameters were set based on Eberhart and Shi (1998), which was showed to be effective by using the hybrid of GA and PSO. These parameters include $T_{\max }(L)=200, T_{\max }(F)=200$, Pop_Size $=200, C_{\text {rate }}=0.8, M_{\text {rate }}=0.15, V_{\max }=10$ and Inertia weight $\hat{I}[0.2,1.2]$.

\subsection{Results and discussions on the case problem}


According to Sections 4.2 and 4.3, the proposed methodology in Section 3 was used to obtain appropriate CTFLP and TRP for the general contractor and the subcontractor, respectively. 50 solutions were selected to provide references for the general contractor and subcontractor after running the program for 50 times. The most satisfactory solution from each run was kept and 50 satisfactory solutions were ultimately obtained. Each satisfactory solution can be decoded as satisfactory CTFLP for the general contractor and satisfactory TRP for the subcontractor. Table 6 shows the best, worst and average objective values based on those 50 satisfactory solutions, showing that the differences between the upper and lower bounds for both the general contractor and subcontractor's objective values are small. This means that the proposed HGABPSO method is able to obtain stable solutions for Hydropower A. Decision makers can have their respective choices of different CTFLP and TRP based on their requirements for different objective values. For example, if the objective value for the general contractor is equal to or better than its desired objectives with specific CTFLP, the CTFLP is acceptable for the general contractor of the project. For the specific CTFLP, there would be corresponding TRP for the subcontractor. If the subcontractor is also satisfied with its objective values for the plan, then the conflicts between the general contractor and the subcontractor is resolved and a satisfactory solution is obtained. In Hydropower A, the CTFLP and the TRP with the lowest objective value for the general contractor is selected and implemented to guide the practical construction operations. Table 6 also shows the appropriate CTFLP for the general contractor in Hydropower A. It is shown that the total estimated costs for the general contractor were $\operatorname{COST}_{L}(x, y)=8.0125^{\prime} 10^{8} R M B$. The total estimated construction and maintenance costs were

$\operatorname{COST}_{F}(x, y)=2.4035^{\prime} 10^{8} R M B$ and the total risks were $\operatorname{RISK}_{F}(x, y)=567.557$. To better illustrate the satisfactory solutions for Hydropower A construction site, Figure 8 is drawn.

The proposed methodology is among the first research to decide on CTFLP based on resolving the conflicts between the CTFLP and the TRP on the construction site. Since the proposed methodology is composed of establishing a MINBLPM in Section 3.1 and proposing the HGABPSO in Section 3.2, both the model comparison and algorithm comparison are applied to demonstrate the effectiveness of the proposed methodology.

\subsubsection{Discussion I: model comparison for the CTFLP}

In past decades, much research has been conducted to decide on the CTFLP for construction projects and the total costs are one of their most commonly-used optimization goals. Further, it is highly stressed by authors that appropriate CTFLP has interactive relationships and conflicts with many other pre-planning tasks. Resolving the conflicts is quite important for obtaining satisfactory solutions for both the CTFLP and other pre-planning tasks. However, little research considers the influences of other pre-planning tasks when deciding on CTFLP. In order to demonstrate that the conflicts are crucial and that the proposed MINBLPM in eq. [12] is helpful for resolving those conflicts, the single level model in eq. [17] for the CTFLP is compared. It assumed that the transport routes are planned when they are needed to transport on-site materials and equipment, which means the total costs and the total risk along with planning and transporting routes are neglected. In eq. [17], the total costs minimization is also considered to be its objective function, however, the conflicts between the CTFLP and the TRP are neglected.

$$
\left\{\begin{array}{l}
\min \operatorname{Cost}=E\left(\tilde{c}_{i m}\right) x_{i m}+\sum_{i, j=1}^{J} \sum_{m, n=1}^{M} E\left(\tilde{Q}_{i j}\right) E\left(\tilde{c}_{i j}\right) d_{m n} x_{i m} x_{j n}+\sum_{i=1}^{J} \sum_{m=1}^{M} \sum_{f=1}^{F} E\left(\tilde{Q}_{i f}\right) E\left(\tilde{c}_{i f}\right) d_{m f} x_{i m}, \\
S_{i} x_{i m} \leq D_{m}, \\
x_{i m^{\prime}}=1, \forall i^{\prime} \in \Xi=\left\{1,2, \ldots, I^{\prime}\right\}, \\
\sum_{m=1}^{M} x_{i m}=1, \forall i \in \Omega=\{1,2, \ldots, J\}, \\
\sum_{i=1}^{J} x_{i m}=1, x_{i m}=\{0,1\}, \forall m^{\prime} \in \Phi=\left\{1,2, \ldots, M^{\prime}\right\},
\end{array}\right.
$$

The proposed HGABPSO in Section 3.2 is also applied to solve eq. [17] for satisfactory solutions. 50 results are also obtained based on 50 runs. Table 7 shows the best, worst and average objective values for Hydropower A. Compared to the objective values and the specific CTFLP from Table 6, the most satisfactory total costs in eq. [17] 
was better than that in eq. [12] for the CTFLP. However, it was reflected from the on-the-spot discussions and communications that although the obtained CTFLP had better objective values, the subcontractor was not able to accept the corresponding TRP and the general contractor-subcontractor structure failed. On the contrary, the CTFLP and the TRP from the proposed methodology were accepted by Hydropower A to guide the practical constructions. Thus, it is concluded that resolving the conflicts between the CTFLP and the TRP is quite important and applying the MINBLPM in eq. [12] is helpful for resolving the conflicts and obtaining appropriate CTFLP.

In summary, resolving the conflicts is crucial for CTFLP as it can prevent further practical conflicts when designing the CTFLP and the TRP.

\subsubsection{Discussion II: algorithm comparison for obtaining satisfactory solutions}

In order to demonstrate the effectiveness of the proposed HGABPSO method in Section 3.2, the GA and the BPSO, which have been widely used for BLPPs, are compared. To begin with, different parameters settings for GA are $T_{\max }(L)=200, T_{\max }(F)=200, P o p_{-}$Size $=200, C_{\text {rate }}=0.8, M_{\text {rate }}=0.15$ and $S_{\text {rate }}=0.3$, and parameters for BPSO are $T_{\max }(L)=200, T_{\max }(F)=200$, Pop_Size $=200, V_{\max }=10$ and Inertia weight 1 I $[0.2,1.2]$. Table 7 showed the best, worst and average objective values based on 50 satisfactory solutions from different methods. It was shown that all the HGABPSO, GA and BPSO were able to obtain satisfactory solutions, however, the HGAPSO was able to obtain better solutions than the GA and the BPSO. The HGABPSO was able to obtain appropriate CTFLP with the total costs of $8.0125^{\prime} 10^{8} R M B$, which was much better than $8.3497^{\prime} 10^{8} R M B$ based on the BPSO and $8.7557^{\prime} 10^{8} R M B$ based on the GA. Further, Figure 9 shows different convergence trends based on three methods, which demonstrates that the proposed HGABPSO in this study had better convergence capacity than both GA and BPSO.

\subsection{Suggestions for the conflicts resolution-based CTFLP}

The proposed methodology is validated to be able to obtain appropriate CTFLP based on the resolution of important conflicts between the CTFLP and the TRP. However, the CTFLP has interactive relationships and incompatible actions with many other pre-planning tasks, such as the raw materials purchasing and the workforces planning. These pre-planning works are carried out by many different parties, such as contractors, subcontractors, A/E engineering and superintendents, thus the conflicts between these interested parties are inevitable (Cheng and O'Connor 1996). Under these circumstances, resolving the conflicts are beneficial for all the pre-planning tasks, such as the CTFLP, the TRP and the workforces planning.

Compared to the extant research on the CTFLP in large-scale construction projects, the authors are among the first to consider that the significant impacts of many pre-planning tasks on the CTFLP. This study proposes an example of deciding on the CTFLP based on the conflicts resolution between the CTFLP and the TRP. It starts from identifying important conflicts in Section 2.1 and proposes a new methodology in Section 3, in which Procedure I establishes a MINBLPM and Procedure II innovates a HGABPSO algorithm for appropriate CTFLP and TRP. The proposed methodology provides a reference for the CTFLP based on the conflicts resolution between the CTFLP and other preplanning tasks. In order to apply the proposed methodology in similar situations, some suggestions are provided below.

Since the general contractor-subcontractors systems are common but with different characteristics in different projects, understanding the general contractor-subcontractors structure for the targeted projects are difficult and important. Identifying the crucial conflicts is the primary step to determine the CTFLP based on conflicts resolution. Under these circumstances, many on-the-spot investigations and surveys are needed to find out the existing structures and identify important conflicts between the general contractor and subcontractors. For example, the planners for the CTFLP have to understand their relationships with other pre-planning tasks to find out if there are any 
incompatible actions or needs (conflicts) that would lead to a failed project. If the conflicts between the planners for the CTFLP and the planners for the workforces planning are crucial, detailed investigations are suggested to identify the conflicts.

To solve the crucial conflicts, the CTFLP problem and the other pre-planning problems can be modelled as hierarchical problems and the MINBLPMs are established. Accordingly, transforming the conceptual conflicts into mathematical functions in the proposed bi-level models is crucial for obtaining feasible solutions. This study provides good examples for modelling practical constraints and requirements. Practical requirements for different pre-planning tasks are modelled in the "objective functions" and constraints are modelled in the "constraints functions". For example, the general contractor in this study attempts to determine the CTFLP with the total costs minimization and the subcontractor aims to minimize its total costs and the total risks for the TRP. However, both decision makers are able to change their objectives based on their respective requirements. Besides, the CTFLP and the other pre-planning works are conducted before the construction of the real-world large-scale construction projects. Estimating the related qualitative and quantitative parameters in the MINBLPMs is difficult and experienced experts are often needed. Those experts cannot provide determined data for the different parameters. Thus, uncertain environments need to be considered to enhance the practicality of the proposed CTFLP. However, since uncertain environments involve fuzzy environment, random environment, fuzzy random environment, bi-fuzzy environment, it is important to figure out the nature of the decision-making environments for the different projects. This study depicts the uncertain parameters with fuzzy random parameters. Fuzzy parameters, random parameters and bi-fuzzy parameters are recommended to depict the real decision-making environments.

To validate the applicability, effectiveness and efficiency of the proposed methodology in practical large-scale construction projects, test problems or practical applications are needed. Since the proposed methodology is a new method for the CTFLP, the practical application is suggested in this study. The results show that the proposed methodology is helpful for both the general contractor and subcontractor for obtaining satisfactory solutions. More practical applications with the similar situations are suggested for further validations.

Environmental impacts, social impacts and total quality management are becoming more and more important for large-scale construction projects. As a result, after determining the CTFLP or other pre-planning tasks, it is necessary to evaluate its environmental and social impacts to check if it is under the regulations of the local government. Besides, the total quality management of large-scale construction projects is quite important since they will be used for decades once established, so further extensions are suggested to consider these aspects when deciding on appropriate CTFLP.

In summary, contracting subcontractors for many pre-planning tasks is quite common in practical large-scale construction projects. The proposed methodology is strongly suggested to resolve conflicts between the general contractor and subcontractor and to obtain appropriate CTFLP for the general contractor. The different general contractor-subcontractor structures need different bi-level models or methods for obtaining satisfactory solutions. Thus, many improvements of this study are suggested to deal with more practical difficulties based on project-by-project characteristics.

\subsection{Conclusions and future research recommendations}

Many pre-planning tasks (such as the CTFLP, the TRP and the schedule planning) are interrelated and conflicts between the general contractor and subcontractors are unavoidable in their task optimizations. Numerous evidences have reported that it was crucial to determine the CTFLP based on the conflicts resolution. This study presented a two procedures-based methodology for CTFLP based on the conflicts resolution between the CTFLP and the TRP in large-scale construction projects. The methodology was composed of establishing a MINBLPM and proposing the HGABPSO to solve the complex model for the ultimatum CTFLP. In Procedure I, the general contractor attempted to minimize the total costs for the CTFLP and the subcontractor aimed to minimize the total construction and maintenance costs as well as the total risks in the TRP. To reflect the inherent uncertainties in the pre-planning tasks, the FRVs were employed, making it more complicated but more practical. To solve the 
complex MINBLPM, Procedure II integrated the BPSO and the mutation and crossover operators from the GA to determine the CTFLP. It was proved that the proposed HGABPSO had better convergence than the respective BPSO and GA in achieving the CTFLP and the TRP from the practical application. The computational results and the post-hoc analysis first showed that the CTFLP from this study were able to avoid many conflicts between the CTFLP and the TRP. Second, the proposed methodology was effective for both the general contractor for the CTFLP and the subcontractors for other pre-planning tasks. Third, the methodology can be adjusted and applied to other circumstances, such as the projects with crucial conflicts between the CTFLP and the workforce planning.

Future extensions of the study may include: an exploration of the dynamic CTFLP based on conflicts resolution; an applicability validation of the methodology in other projects; an improvement of the methodology for determining the CTFLP based on the conflicts resolution between the CTFLP and the other tasks simultaneously (such as the raw materials purchasing, the workforce planning, the TRP); and an enrichment of the methodology to prevent more kinds of conflicts.

\section{Acknowledgements}

This research was supported by the [Key Program of National Natural Science Foundation of China] under Grant [number 70831005], [“985" Program of Sichuan University (Innovative Research Base for Economic Development and Management)], the [Research Foundation of Ministry of Education for the Doctoral Program of Higher Education of China] under Grant [number 20130181110063], and the [Program of China Scholarships Council] under Grant [number 201506240179].

\section{References}

Al-Khayyal, F.A, Horst, R., and Pardalos, P.M. 1992. Global optimization of concave function subject to quadratic constraints: An application in nonlinear bilevel programming. Annals of Operations Research, 34(1): 125-147.

Amouzegar, M.A. 1999. A global optimization method for nonlinear bilevel programming problems. Systems, Man, and Cybernetics, Part B: Cybernetics, IEEE Transactions on, 29(6): 771-777.

Arditi, D., and Chotibhongs, R. 2005. Issues in subcontracting practice. Journal of Construction Engineering and Management, 131(8): 866-876.

Bard, J.F. 1991. Some properties of the bilevel programming problem. Journal of Optimization Theory and Applications, 68(2): 371-378.

Berman, O., Verterb, V., and Karac, B. 2007. Designing emergency response networks for hazardous materials transportation, Computers and Operations Research, 34(5): 1374-1388. 
Chang, H.C., Tsai, H.T., and Liu, T.K. 2014. Application of genetic algorithm to optimize unrelated parallel machines of flexible job-shop scheduling problem. Control \& Automation (ICCA), 11th IEEE International Conference on, 596-599.

Cheng, M.Y., and O’Connor, J.T. 1996. ArcSite: enhanced GIS for construction site layout. Journal of Construction Engineering and Management, 122(4): 329-336.

Du, S., Li, W., and Cao, K. 2006. A learning algorithm of artificial neural network based on GA-PSO. The Sixth World Congress on Intelligent Control and Automation WCICA, IEEE, 1: 3633-3637.

Eberhart, R.C., and Shi, Y. 1998. Comparison between genetic algorithms and particle swarm optimization. Evolutionary Programming VII, Springer Berlin Heidelberg, 611-616.

Edmunds, T.A., and Bard, J.F. 1992. An algorithm for the mixed-integer nonlinear bilevel programming problem. Annals of Operations Research, 34(1): 149-162.

Elazouni, A.M., and Metwally, F.G. 2000. D-SUB: Decision support system for subcontracting construction works. Journal of construction engineering and management, 126(3): 191-200.

Elbeltagi, E., Hegazy, T., and Eldosouky, A. 2004. Dynamic layout of construction temporary facilities considering safety. Journal of Construction Engineering and Management, 130(4): 534-541.

El-Rayes, K., and Khalafallah, A. 2005. Trade-off between safety and cost in planning construction site layouts. Journal of Construction Engineering and Management, 131(11): 1186-1195.

El-Rayes, K., and Said, H. 2009. Dynamic site layout planning using approximate dynamic programming. Journal of Computing in Civil Engineering, 23(2): 119-127.

Fan, S.K.S., Liang, Y.C., and Zahara, E. 2006. A genetic algorithm and a particle swarm optimizer hybridized with Nelder-Mead simplex search. Computers \& Industrial Engineering, 40(4): 401-425.

Fan, S.K.S., and Zahara, E. 2007. A hybrid simplex search and particle swarm optimization for unconstrained optimization. European Journal of Operational Research, 181(2): 527-548. 
Farvaresh, H., and Sepehri, M.M. 2013. A branch and bound algorithm for bi-level discrete network design problem.

Networks and Spatial Economics,13(1): 67-106.

Gipps, P.G., Gu, K.Q., Held, A., and Barnett, G. 2001. New technologies for transport route selection. Transportation

Research Part C, 9(2): 135-154.

Goldberg, D.E. 1989. Genetic algorithm in search, optimization \& machine learning. Addison-Wesley, Reading, MA.

Gümü s, Z.H., and Floudas, C.A. 2001. Global optimization of nonlinear bilevel programming problems. Journal of Global Optimization, 20(1): 1-31.

Hamouda, G., Saccomanno, F., and Fu, L. 2004. Quantitative risk assessment decision-support model for locating hazardous materials teams. Transportation Research Record, 1873(1): 1-8.

Hinze, J., and Tracey, A. 1994. The contractor-subcontractor pelationship: the subcontractor's view. Journal of Construction Engineering and Management, 120(2): 274-287.

Holland, J.H. 1975. Adaptation in natural and artificial systems. University of Michigan Press, Michigan, US.

Horn, J., Nafpliotis, N., and Goldberg, D.E. 1994. A niched Pareto genetic algorithm for multiobjective optimization. Evolutionary Computation, IEEE World Congress on Computational Intelligence, Proceedings of the First IEEE Conference on, 82-87.

Hu, X., and Eberhart, R. 2002. Multiobjective optimization using dynamic neighborhood particle swarm optimization. Computational Intelligence, Proceedings of the World on Congress on, 2: 1677-1681.

Humphreys, P., Matthews, J., and Kumaraswamy, M. 2003. Pre-construction project partnering: from adversarial to collaborative relationships. Supply Chain Management: An International Journal, 8(2): 166-178.

International Commission on Large Dams, 1998. Register of Large Dams. ICOLD, Paris.

Nuortio, T., Kytöjoki, J., Niska, H., and Bräysy, O. 2008. Improved route planning and scheduling of waste collection and transport. Expert Systems with Applications, 30: 223-232. 
Jan, R.H., and Chern, M.S. 1994. Nonlinear integer bilevel programming. European Journal of Operational Research, 72(3): 574-587.

Jeong, Y.W., Park, J.B., Jang, S.H., and Lee, K.Y. 2010. A new quantum-inspired binary PSO: application to unit commitment problems for power system. IEEE transactions on power systems, 25(3): 1486-1495.

Jeroslow, R.G. 1985. The polynomial hierarchy and simple model for competitive analysis. Mathematical programming, 32(2): 146-164.

[31] Kao, Y.T., and Zahara, E. 2007. A hybrid genetic algorithm and particle swarm optimization for multimodal functions. Applied Soft Computing, 8(2): 849-857.

Kasemset, C., and Kachitvichyanukul, V. 2012. A PSO-based procedure for a bi-level multi-objective TOC-based job-shop scheduling problem. International Journal of Operational Research, 14(1): 50-69.

Kennedy, J., and Eberhart, R.C. 1995. Particle swarm optimization. Proc. IEEE Int. Conf. Neural Networks (ICNN'95), Perth, Australia, IV, 1942-1948.

Kennedy, J., and Eberhart, R.C. 1997. A discrete binary version of the particle swarm algorithm. Systems, Man, and Cybernetics. Computational Cybernetics and Simulation., 1997 IEEE International Conference on, 5: 4104-4108.

Kennedy, J., and Eberhart, R.C. 2001. Swarm Intelligence. San Francisco, CA: Morgan Kaufmann.

Kuo, R.J., and Han, Y.S. 2011. A hybrid of genetic algorithm and particle swarm optimization for solving bi-level linear programming problem-A case study on supply chain model. Applied Mathematical Modelling, 35(8): 3905-3917.

Kwakernaak, H. 1978. Fuzzy random variables-I. Definitions and theorems. Information Sciences, 15(1): 1-29.

Li, H.C., and Wang, Y.P. 2008. Exponential distribution-based genetic algorithm for solving mixed-integer bilevel programming problems. Journal of Systems Engineering and Electronics, 19(6): 1157-1164.

Liu, B. 2002. Random fuzzy dependent-chance programming and its hybrid intelligent algorithm. Information Sciences, 141(3): 259-271. 
Ma, W., Wang, M., and Zhu, X. 2014. Improved particle swarm optimization based approach for bilevel programming problem-an application on supply chain model. International Journal of Machine Learning and Cybernetics, 5(2): 281-292.

Miller, T., Friesz, T., and Robin, R. 1992. Heuristic algorithms for delivered price spatially competitive network facility location problems. Annals of Operations Research, 34(1): 177-202.

Mohemmed, A.W., Sahoo, N.C., and Geok, T.K. (2008). Solving shortest path problem using particle swarm optimization. Applied Soft Computing Journal,8(4): 1643-1653.

Moller, B., and Reuter, U. 2007. Uncertainty Forecasting in Engineering. Springer.

Neungmatcha, W., Sethanan, K., Chien, C.F., and Gen, M. 2012. Capacitated location-allocation problem for multi-facility services in sugarcane supply system by adaptive genetic algorithm. Proceedings of The 16th Asia Pacific Symposium on Intelligent and Evolutionary Systems.

Oduguwa, V., and Roy, R. 2002. Bi-level optimisation using genetic algorithm. Artificial Intelligence Systems (ICAIS 2002) 2002 IEEE International Conference on, 322-327.

Osman, M.S., Abo-Sinna, M.A., Amer, A.H., and Emam, O.E. 2004. A multi-level non-linear multi-objective decision-making under fuzziness. Applied Mathematics and Computation, 153(1): 239-252.

Park, J.B., Lee, K.S., Shin, J.R., and Lee, K.Y. 2005. A particle swarm optimization for economic dispatch with nonsmooth cost functions. Power Systems, IEEE Transactions on, 20(1): 34-42.

Pei, Z., Tian, S., and Huang, H. 2006. A novel method for solving nonlinear bilevel programming based on hybrid particle swarm optimization. 2006 8th International Conference on Signal Processing, 3.

Pẽna-Mora, F., Sosa, C. E., and McCone, D. S. 2003. Introduction to construction dispute resolution. Prentice Hall.

Sadeghpour, F., and Andayesh, M. 2015. The constructs of site layout modeling: an overview. Canadian Journal of Civil Engineering. 42(3): 199-212. 
Sakawa, M. 2000. Computational methods through genetic algorithms for obtaining Stackelberg solutions to two-level mixed zero-one programming problems. Cybernetics \& Systems, 31(2): 203-221.

Sakawa, M., and Nishizaki, I. 2009. Cooperative and noncooperative multi-level programming [electronic resource], 48. Springer.

Sakawa, M. and Shibano, T. 1997. Multiobjective fuzzy satisficing methods for 0-1 knapsack problems through genetic algorithms. Fuzzy Evolutionary Computation, W. Pedrycs (ed.), Kluwer Academic Publishers, Boston, $155-177$.

Scudder, T. 2005. The Future of Large Dams: Dealing with Social, Environmental, Institutional and Political Costs. Earthscan, London.

Shafaat, A., Mahfouz, T., Jackson, C., and Kandil, A. 2014. Decision-making model by specialty subcontractors in construction projects. In Construction Research Congress Construction in a Global Network, 867-876.

Soltani, A.R., Tawfik, H., Goulermas, J.Y., and Fernando, T. 2002. Path planning in construction sites: performance evaluation of the Dijkstra and GA search algorithms. Advanced Engineering Informatics, 16(4): 291-303.

Vasconcelos, J.A., Ramirez, J.A., Takahashi, R.H.C., and Saldanha, R.R. 2001. Improvements in genetic algorithms. Magnetics, IEEE Transactions on,37(5): 3414-3417.

Vicente, L., Savard, G., and Judice, J. 1994. Descent approach for quadratic bilevel programming. Journal of Optimization Theory and Applications,81(2): 379-399.

Wang, Y.P., Jiao, Y.C., and Li, H. 2005. An evolutionary algorithm for solving nonlinear bilevel programming based on a new constraint-handling scheme. IEEE transactions on systems, man, and cybernetics-Part C: applications and reviews, 35(2): 221-232.

Xu, J.P., Gang, J., and Lei, X. 2013. Hazmats transportation network design model with emergency response under complex fuzzy environment. Mathematical Problems in Engineering. http://dx.doi.org/10.1155/2013/517372. 
Xu, J.P., and Liu, Y.G. 2008. Multiobjective decision making model under fuzzy random environment and its application to inventory problems. Information Sciences, 178(14): 2899-2914.

Xu, J.P., and Song, X.L. 2014. Suggestions for temporary construction facilities' layout problems in large-scale construction projects. Journal of Construction Engineering and Management, 140(5): 06014001.

Xu, J.P., Tu, Y., and Zeng, Z.Q. 2013. Bi-level optimization of regional water resources allocation problem under fuzzy random environment. Journal of Water Resources Planning and Management, 139(3): 246-264.

Xu, J.P., and Zhou, X.Y. 2009. Fuzzy-like multiple objective decision making. Springer.

Yeo, H., Yoon, Y., and Madanat, S. 2013. Algorithms for bottomup maintenance optimisation for heterogeneous infrastructure systems. Structure and Infrastructure Engineering, 9: 317-328.

Yin, Y.F. 2000. Genetic-algorithms-based approach for bilevel programming models. Journal of Transportation Engineering, 126(2): 115-120.

Zhong, D., Li, J., Zhu, H., and Song, L. 2004. Geographic information system-based visual simulation methodology and its application in concrete dam construction processes. Journal of construction engineering and management, 130(5), 742-750.

Zografos, K.G., and Androutsopoulos, K.N. 2008. A decision support system for integrated hazardous materials routing and emergency response decisions. Transportation Research C, 16(6): 684-703.

Zouein, P.P., and Tommelein, I.D. 1999. Dynamic layout planning using a hybrid incremental solution method. Journal of Construction Engineering and Management, 125(6): 400-408.

Zouein, P.P., Harmanani, H., and Hajar, A. 2002. Genetic algorithm for solving site layout problem with unequal-size and constrained facilities. Journal of computing in civil engineering, 16(2): 143-151. 


\title{
List of symbols (LoS)
}

\section{LoS.1. Notations for the proposed MINBLPM in Procedure I}

\author{
Subscripts and sets \\ $\Omega$ : set of CTFs, $i, j \in \Omega=\{1,2, \ldots, J\}$; \\ $\Phi$ : set of PFLs, $m, n \in \Phi=\{1,2, \ldots, M\}$; \\ $\Upsilon$ : set of fixed facilities, $f \in \Upsilon=\{1,2, \ldots, F\}$; \\ $\Lambda$ : set of emergency response teams, $t \in \Lambda=\{1,2, \ldots, T\}$.
}

\section{Parameters}

$\tilde{\bar{c}}_{i m}:$ the setup and closure cost for CTF i at PFL m;

$\tilde{\bar{c}}_{i j}$ : the unit cost for transporting materials between CTFs i and $\mathrm{j}$;

$\tilde{\bar{c}}_{i f}$ : the unit cost for transporting materials between CTF $\mathrm{i}$ and fixed facility $\mathrm{f}$;

$d_{m n}:$ the real distance between PFL $\mathrm{m}$ and PFL $\mathrm{n}$;

$d_{m f}$ : the real distance between PFL $\mathrm{m}$ and fixed facility $\mathrm{f}$;

$\tilde{\bar{Q}}_{i j}$ : the interactive exchange of materials between CTF $\mathrm{i}$ and $\mathrm{CTF} \mathrm{j}$;

$\tilde{\bar{Q}}_{i f}$ : the interactive exchange of materials between CTF $\mathrm{i}$ and fixed facility f;

$S_{i}$ : the area of CTF i;

$D_{m}:$ the area of PFL m;

$\tilde{\bar{c}}_{m n}$ : the unit cost of constructing and maintaining route between PFL $\mathrm{m}$ and PFL $\mathrm{n}$;

$\tilde{\bar{c}}_{m f}$ : the unit cost of constructing and maintaining route between PFL $\mathrm{m}$ and fixed facility $\mathrm{f}$;

$\tilde{\bar{r}}_{m n}$ : the unit distance risk of constructing route between PFL $\mathrm{m}$ and PFL $\mathrm{n}$;

$\tilde{\bar{r}}_{m f}$ : the unit distance risk of constructing route between PFL $\mathrm{m}$ and fixed facility $\mathrm{f}$;

$\alpha_{1}$ : the risk decrease coefficient when the route between PFL $\mathrm{m}$ and PFL $\mathrm{n}$ is covered by an emergency response team;

$\alpha_{2}$ : the risk decrease coefficient when the route between PFL $m$ and fixed facility $\mathrm{f}$ is covered by an emergency response team;

$D_{\max }:$ the maximum service distance for emergency response teams;

$T$ : the total emergency response teams;

$h_{m n}^{t}$ : the route between PFL $\mathrm{m}$ and PFL $\mathrm{n}$ is covered by the emergency response team $\mathrm{t}$;

$D_{m n}^{t}:$ the shortest distance from the emergency response team $\mathrm{t}$ to the midpoint of the route between PFL mand PFL $\mathrm{n}$;

$\operatorname{COST}_{L}$ : the total interactive cost for the general contractor when deciding on the CTFLP;

$\operatorname{COST}_{F}$ : the total constructing cost for the subcontractor when planning transport routes on the construction site;

RISK $_{F}$ : The total risk for the subcontractor when constructing transport routes on the construction site.

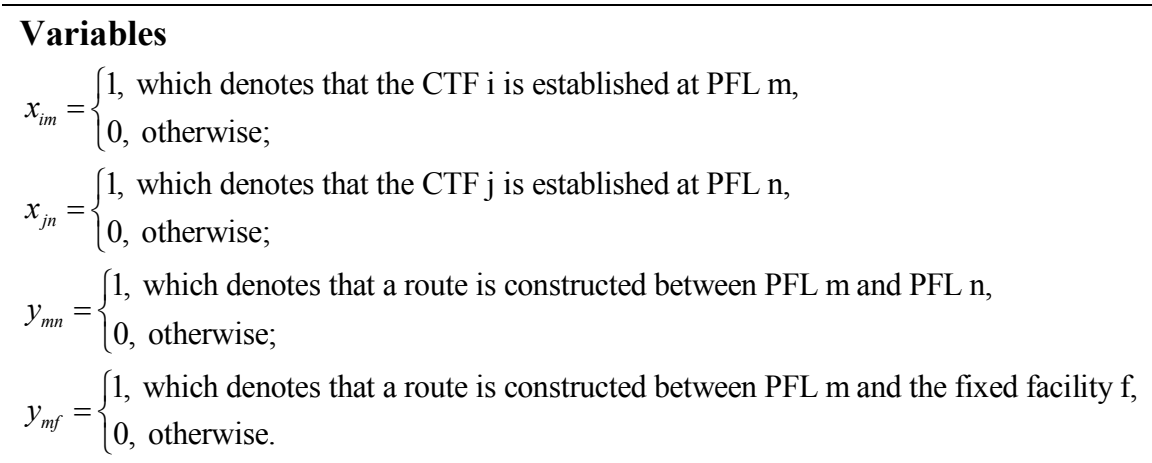




\section{LoS.2. Notations for the proposed HGABPSO in Procedure II}

$o(L)_{a}:$ the position of the $\mathrm{a}^{\text {th }}$ particle for the CTFLP problem, $o(L)_{a}=\left\{x_{i m}, x_{j n}\right\}$;

$o(F)_{a}:$ the position of the $\mathrm{a}^{\text {th }}$ particle for the TRP problem, $o(F)_{a}=\left\{y_{m n}, y_{m f}\right\}$;

$O_{a}$ : the position of the $\mathrm{a}^{\text {th }}$ particle for the proposed eq. [12], $O_{a}=\left\{o(L)_{a}, o(F)_{a}\right\}$;

$v_{o(L)_{a}}:$ the velocity of $o(L)_{a}$ for the CTFLP problem;

$v_{o(F)_{a}}:$ the velocity of $o(F)_{a}$ for the TRP problem;

$V_{\max }$ : the maximal velocity for both the $v_{o(L)_{a}}$ and $v_{o(F) a}$;

Pop_Size : the population size for both the CTFLP and the TRP problems;

$t(L)$ : the present iteration number of the CTFLP problem;

$t(F)$ : the present iteration number of the TRP problem;

$w$ : the inertia weight;

$c_{1}, c_{2}:$ the learning factors;

Rand $_{1}$, Rand $_{2}$, Rand $_{a b}:$ the random numbers in the interval $[0,1]$;

$d_{1}, d_{2}, d_{3}$ : the weights for objectives $\operatorname{COST}_{L}(x, y), \operatorname{COST}_{F}(x, y), R I S K_{L}(x, y)$, respectively;

$\operatorname{COST}_{L}^{\max }, \operatorname{COST}_{F}^{\max }, \operatorname{RISK}_{F}^{\text {max }}$ : the maximal values for objectives $\operatorname{COST}_{L}(x, y), \operatorname{COST}_{F}(x, y), \operatorname{RISK}_{L}(x, y)$, respectively;

$T_{-\max (L)}:$ the maximal iteration number for $t(L)$;

$T_{-\max (F)}:$ the maximal iteration number for $t(F)$;

$C_{\text {rate }}:$ the crossover rate;

$M_{\text {rate }}:$ the mutation rate;

$S\left(v_{a b}^{t+1}\right)$ : the intermediate variable, representing a probability threshold. 


\section{TABLES}

Table 1: Name list for CTFs and PLFs with their properties in Hydropower A (unit: m)

\begin{tabular}{|c|c|c|c|c|c|c|}
\hline \multicolumn{7}{|c|}{ List for CTFs } \\
\hline Facilities & CTF 1 & CTF 2 & CTF 3 & CTF 4 & CTF 5 & CTF 6 \\
\hline Facility item & $\begin{array}{l}\text { Labor } \\
\text { Residence }\end{array}$ & Maintenance Shop & Stone \& Sand & Steel Storage & Carpentry Shop & Explosive Storage \\
\hline Length & 30 & 70 & 60 & 60 & 40 & 60 \\
\hline Width & 25 & 45 & 50 & 40 & 40 & 50 \\
\hline Facilities & CTF 7 & CTF 8 & CTF 9 & CTF 10 & CTF 11 & CTF 12 \\
\hline Facility item & Warehouse & Oil Depot & First Aid & $\begin{array}{l}\text { Mental } \\
\text { Installing }\end{array}$ & Equipment Repair & Offices \\
\hline Length & 60 & 35 & 40 & 50 & 75 & 60 \\
\hline Width & 45 & 30 & 30 & 50 & 60 & 55 \\
\hline Facilities & CTF 13 & CTF 14 & CTF 15 & CTF 16 & CTF 17 & CTF 18 \\
\hline Facility item & Concrete Shop & Rebar Shop & $\begin{array}{l}\text { Reinforcing } \\
\text { Steel Shop }\end{array}$ & $\begin{array}{l}\text { Drill Tools } \\
\text { Repair }\end{array}$ & Batch Plant & Welding Shop \\
\hline Length & 50 & 55 & 65 & 45 & 30 & 30 \\
\hline Width & 30 & 50 & 55 & 40 & 20 & 25 \\
\hline \multicolumn{7}{|c|}{ List for PLFs } \\
\hline PFL No. & 1 & 2 & 3 & 4 & 5 & 6 \\
\hline Length & 56 & 79 & 83 & 57 & 48 & 50 \\
\hline Width & 45 & 45 & 63 & 48 & 35 & 40 \\
\hline PFL No. & 7 & 8 & 9 & 10 & 11 & 12 \\
\hline Length & 43 & 66 & 56 & 47 & 63 & 70 \\
\hline Width & 35 & 50 & 45 & 25 & 54 & 55 \\
\hline PFL No. & 13 & 14 & 15 & 16 & 17 & 18 \\
\hline Length & 60 & 50 & 55 & 60 & 55 & 64 \\
\hline Width & 45 & 45 & 50 & 55 & 45 & 56 \\
\hline PFL No. & 19 & 20 & 21 & 22 & 23 & 24 \\
\hline Length & 70 & 55 & 50 & 45 & 35 & 50 \\
\hline Width & 62 & 50 & 45 & 30 & 30 & 40 \\
\hline PFL No. & 25 & 26 & 27 & 28 & 29 & 30 \\
\hline Length & 45 & 30 & 30 & 35 & 40 & 50 \\
\hline Width & 35 & 25 & 25 & 30 & 35 & 45 \\
\hline
\end{tabular}


Table 2: The costs $\tilde{\bar{c}}_{i m}$ for building up, running, maintaining and closing CTF $i$ at PFL $m$ (Part) (unit: $10^{3} R M B$ )

\begin{tabular}{lccccc}
\hline \hline$\tilde{\bar{c}}_{i m}$ & PFL 3 & PFL 6 & PFL 9 & PFL 12 & PFL 15 \\
\hline CTF 1 & $\left(17.29, r_{1-3}, 19.26\right)$ & $\left(16.37, r_{1-6}, 18.56\right)$ & $\left(18.61, r_{1-9}, 21.37\right)$ & $\left(13.77, r_{1-12}, 16.93\right)$ & $\left(15.67, r_{1-15}, 17.91\right)$ \\
& $r_{1-3} \sim N(18.75,3)$ & $r_{1-6} \sim N(17.73,3)$ & $r_{1-9} \sim N(19.37,3)$ & $r_{1-12} \sim N(14.26,5)$ & $r_{1-15} \sim N(16.32,4)$ \\
CTF 5 & $\left(20.55, r_{5-3}, 25.75\right)$ & $\left(19.25, r_{5-6}, 23.65\right)$ & $\left(21.36, r_{5-9}, 24.50\right)$ & $\left(19.75, r_{5-12}, 23.50\right)$ & $\left(18.55, r_{5-15}, 21.25\right)$ \\
& $r_{5-3} \sim N(23.86,5)$ & $r_{5-6} \sim N(22.35,4)$ & $r_{5-9} \sim N(23.25,3)$ & $r_{5-12} \sim N(21.45,4)$ & $r_{5-15} \sim N(19.37,3)$ \\
CTF 10 & $\left(15.75, r_{10-3}, 20.15\right)$ & -- & $\left(15.35, r_{10-9}, 19.45\right)$ & $\left(21.35, r_{10-12}, 25.47\right)$ & $\left(20.25, r_{10-15}, 24.75\right)$ \\
& $r_{10-3} \sim N(16.25,5)$ & - & $r_{10-9} \sim N(17.83,4)$ & $r_{10-12} \sim N(23.15,4)$ & $r_{10-15} \sim N(23.15,4)$ \\
CTF 16 & $\left(23.32, r_{16-3}, 25.85\right)$ & $\left(20.21, r_{16-6}, 24.55\right)$ & $\left(20.32, r_{16-9}, 25.75\right)$ & $\left(27.25, r_{16-12}, 32.15\right)$ & $\left(18.35, r_{16-15}, 22.14\right)$ \\
& $r_{16-3} \sim N(24.53,2)$ & $r_{16-6} \sim N(22.35,4)$ & $r_{16-9} \sim N(22.35,5)$ & $r_{16-12} \sim N(30.13,5)$ & $r_{16-15} \sim N(20.25,4)$ \\
\hline \hline
\end{tabular}


Table 3: $\tilde{\bar{c}}_{i j}, \tilde{\overline{c_{i f}}}$ : denoting the unit cost of materials interaction; $\tilde{\bar{Q}}_{i j}, \tilde{\bar{Q}}_{i f}$ : denoting the interactive exchange of materials between CTF $i$ and CTF $j$ and fixed facility $f$ (Part)(unit: $R M B, t$ )

\begin{tabular}{|c|c|c|c|c|c|c|}
\hline CTFs & Index & CTF 2 & CTF 6 & CTF 14 & fixed facility 1 & fixed facility 2 \\
\hline CTF & $\tilde{\bar{c}}_{i j}$ or & $\left(0.153, \hbar_{3-2}, 0.221\right)$ & $\left(0.115, \hbar_{3-6}, 0.172\right)$ & $\left(0.201, \hbar_{3-14}, 0.283\right)$ & $\left(0.137, J_{3-1}, 0.197\right)$ & $\left(0.145, J_{3-2}, 0.165\right)$ \\
\hline \multirow[t]{3}{*}{3} & & $\hbar_{3-2} \sim N(0.175,5)$ & $\hbar_{3-6} \sim N(0.145,5)$ & $\hbar_{3-14} \sim N(0.254,6)$ & $J_{3-1} \sim N(0.155,5)$ & $J_{3-2} \sim N(0.150,2)$ \\
\hline & $\tilde{\bar{Q}}_{i j}$ or & $\left(1.750, V_{3-2}, 2.131\right)$ & $\left(2.735, V_{3-6}, 3.015\right)$ & $\left(2.305, V_{3-14}, 2.750\right)$ & $\left(49.515, k_{3-1}, 52.500\right)$ & $\left(44.375, k_{3-2}, 48.375\right)$ \\
\hline & $\bar{Q}_{i f}$ & $V_{3-2} \sim N(1.850,4)$ & $V_{3-6} \sim N(2.885,3)$ & $V_{3-14} \sim N(2.515,4)$ & $k_{3-1} \sim N(50.375,3)$ & $k_{3-2} \sim N(46.015,4)$ \\
\hline CTF & $\tilde{\bar{c}}_{i j}$ or & $\left(0.145, \hbar_{4-2}, 0.210\right)$ & $\left(0.103, \hbar_{4-6}, 0.157\right)$ & $\left(0.175, \hbar_{4-14}, 0.215\right)$ & $\left(0.122, J_{4-1}, 0.146\right)$ & $\left(0.130, J_{4-2}, 0.169\right)$ \\
\hline \multirow[t]{3}{*}{4} & & $\hbar_{4-2} \sim N(0.195,6)$ & $\hbar_{4-6} \sim N(0.135,5)$ & $\hbar_{4-14} \sim N(0.180,4)$ & $J_{4-1} \sim N(0.120,2)$ & $J_{4-2} \sim N(0.146,3)$ \\
\hline & $\bar{Q}_{i j}$ or & $\left(2.015, V_{4-2}, 2.335\right)$ & $\left(2.950, V_{4-6}, 3.335\right)$ & $\left(2.175, V_{4-14}, 2.650\right)$ & $\left(35.755, k_{4-1}, 39.950\right)$ & $\left(40.750, k_{4-2}, 44.500\right)$ \\
\hline & $\bar{Q}_{i f}$ & $V_{4-2} \sim N(2.107,3)$ & $V_{4.6} \sim N(3.125,4)$ & $V_{4-14} \sim \mathrm{N}(2.430,5)$ & $k_{4-1} \sim N(37.150,4)$ & $k_{4-2} \sim N(41.750,4)$ \\
\hline CTF & $\tilde{\bar{c}}_{i j}$ or & $\left(0.105, \hbar_{7-2}, 0.143\right)$ & $\left(0.156, \hbar_{7-6}, 0.198\right)$ & $\left(0.151, \hbar_{7-14}, 0.204\right)$ & $\left(0.128, J_{7-1}, 0.169\right)$ & $\left(0.138, J_{7-2}, 0.179\right)$ \\
\hline \multirow[t]{3}{*}{7} & & $\hbar_{7-2} \sim N(0.125,5)$ & $\hbar_{7-6} \sim N(0.168,4)$ & $\hbar_{7-14} \sim N(0.165,5)$ & $J_{7-1} \sim N(0.144,4)$ & $J_{7-2} \sim N(0.162,4)$ \\
\hline & $\bar{Q}_{i j} \quad$ or & $\left(1.885, V_{7-2}, 2.235\right)$ & $\left(2.445, V_{7-6}, 2.975\right)$ & $\left(2.150, V_{7-14}, 2.655\right)$ & $\left(36.600, k_{7-1}, 39.450\right)$ & $\left(40.700, k_{7-2}, 44.350\right)$ \\
\hline & $\bar{Q}_{i f}$ & $V_{7-2} \sim N(2.019,3)$ & $V_{7.6} \sim N(2.650,5)$ & $V_{7-14} \sim N(2.370,5)$ & $k_{7-1} \sim N(38.200,3)$ & $k_{7-2} \sim N(42.9004)$ \\
\hline CTF & $\tilde{\bar{c}}_{i j}$ or & $\left(0.120, \hbar_{15-2}, 0.155\right)$ & $\left(0.125, \hbar_{15-6}, 0.165\right)$ & $\left(0.235, \hbar_{15-14}, 0.287\right)$ & $\left(0.129, J_{15-1}, 0.175\right)$ & $\left(0.135, J_{15-2}, 0.177\right)$ \\
\hline \multirow[t]{3}{*}{15} & $\tilde{\overline{c_{i f}}}$ & $\hbar_{15-2} \sim N(0.137,3)$ & $\hbar_{15-6} \sim N(0.147,4)$ & $\hbar_{15-14} \sim N(0.265,5)$ & $J_{15-1} \sim N(0.149,5)$ & $J_{15-2} \sim N(0.156,4)$ \\
\hline & $\begin{array}{l}\bar{Q}_{i j} \text { or } \\
\tilde{\bar{Q}}_{i f}\end{array}$ & $\left(1.255, V_{15-2}, 1.650\right)$ & $\left(2.055, V_{15-6}, 2.447\right)$ & $\left(2.150, V_{15-14}, 2.460\right)$ & $\begin{array}{c}(42.250 \\
\left.k_{15-1}, 47.455\right)\end{array}$ & $\begin{array}{c}(40.550 \\
\left.k_{15-2}, 44.500\right)\end{array}$ \\
\hline & & $V_{15-2} \sim N(1.350,4)$ & $V_{15-6} \sim N(2.300,4)$ & $V_{15-14} \sim N(2.375,3)$ & $k_{15-1} \sim N(44.355,5)$ & $k_{15-2} \sim N(43.150,4)$ \\
\hline
\end{tabular}


Table 4: $d_{m n}, d_{m f}$ : denoting the distances between PFLs $m$ and $n$ and fixed facility $f$ (Part)(unit: $m$ )

\begin{tabular}{|c|c|c|c|c|c|c|c|c|c|c|c|c|c|c|c|}
\hline $\begin{array}{c}d_{m n} \text { or } \\
d_{m f}\end{array}$ & PFL 1 & $\begin{array}{c}\text { PFL } \\
\mathbf{3} \\
\end{array}$ & $\begin{array}{c}\text { PFL } \\
5 \\
\end{array}$ & $\begin{array}{c}\text { PFL } \\
7 \\
\end{array}$ & $\begin{array}{c}\text { PFL } \\
9 \\
\end{array}$ & $\begin{array}{c}\text { PFL } \\
11 \\
\end{array}$ & $\begin{array}{c}\text { PFL } \\
13 \\
\end{array}$ & $\begin{array}{c}\text { PFL } \\
15 \\
\end{array}$ & $\begin{array}{c}\text { PFL } \\
17 \\
\end{array}$ & $\begin{array}{c}\text { PFL } \\
19 \\
\end{array}$ & $\begin{array}{c}\text { PFL } \\
21 \\
\end{array}$ & $\begin{array}{c}\text { PFL } \\
23 \\
\end{array}$ & $\begin{array}{c}\text { PFL } \\
25 \\
\end{array}$ & $\begin{array}{c}\text { PFL } \\
27 \\
\end{array}$ & $\begin{array}{c}\text { PFL } \\
29 \\
\end{array}$ \\
\hline PFL 2 & 50,965 & 10,350 & 53,780 & 30,450 & 35,130 & 23,980 & 56,180 & 59,160 & 56,540 & 50,950 & 42,540 & 29,064 & 7,750 & 30,870 & 13,600 \\
\hline PFL 8 & 41,350 & 49,600 & 7,950 & 13,580 & 11,590 & 40,560 & 10,450 & 19,450 & 35,450 & 50,440 & 51,465 & 58,465 & 38,620 & 21,355 & 33,460 \\
\hline PFL 14 & 50,450 & 21,580 & 48,750 & 34,335 & 35,780 & 12,270 & 44,450 & 50,250 & 41,459 & 28,785 & 21,580 & 4,950 & 26,560 & 40,250 & 21,355 \\
\hline $\begin{array}{c}\text { Fixed } \\
\text { facility } 1\end{array}$ & 27,130 & 26,590 & 20,940 & 7,780 & 2,350 & 11,915 & 11,255 & 16,560 & 14,590 & 16,450 & 15,350 & 15,580 & 20,755 & 17,450 & 18,580 \\
\hline $\begin{array}{c}\text { Fixed } \\
\text { facility } 3\end{array}$ & 29,130 & 40,590 & 20,940 & 11,780 & 8,690 & 30,915 & 11,255 & 14,560 & 13,590 & 31,450 & 33,350 & 37,580 & 32,755 & 26,450 & 28,580 \\
\hline
\end{tabular}


Table 5: $\tilde{\bar{c}}_{m n}, \tilde{\bar{c}}_{m f}, \tilde{\bar{r}}_{m n}, \tilde{\bar{r}}_{m f}$ denoting the unit construction and maintenance cost/unit risk between PFLs $m$ and $n$ and fixed facility $f$ (Part)

\begin{tabular}{|c|c|c|c|c|c|}
\hline \multicolumn{6}{|c|}{ The unit construction and maintenance cost (unit: $R M B$ ) } \\
\hline$\tilde{\bar{c}}_{m n}$ or $\tilde{\bar{c}}_{m f}$ & PFL 3 & PFL 8 & PFL 15 & PFL 20 & PFL 26 \\
\hline \multirow[t]{2}{*}{ PFL 1} & $\left(16.550, \ell_{1-3}, 20.300\right)$ & $\left(13.400, \ell_{1-8}, 16.650\right)$ & $\left(10.500, \ell_{1-15}, 14.650\right)$ & $\left(14.350, \ell_{1-20}, 18.900\right)$ & $\left(11.300, \ell_{1-26}, 15.150\right)$ \\
\hline & $\ell_{1-3} \sim N(18.500,4)$ & $\ell_{1-8} \sim N(14.550,3)$ & $\ell_{1-15} \sim N(12.500,4)$ & $\ell_{1-20} \sim N(17.500,4)$ & $\ell_{1-26} \sim \mathrm{N}(13.050,4)$ \\
\hline \multirow[t]{2}{*}{ PFL 10} & $\left(17.455, \ell_{10-3}, 21.530\right)$ & $\left(13.300, \ell_{10-8}, 16.750\right)$ & $\left(12.700, \ell_{10-15}, 16.950\right)$ & $\left(13.750, \ell_{10-20}, 17.800\right)$ & $\left(11.100, \ell_{10-26}, 15.560\right)$ \\
\hline & $\ell_{10-3} \sim N(19.500,4)$ & $\ell_{10-8} \sim N(15.500,3)$ & $\ell_{10-15} \sim N(14.550,4)$ & $\ell_{10-20} \sim \mathrm{N}(15.205,4)$ & $\ell_{10-26} \sim \mathrm{N}(13.450,4)$ \\
\hline Fixed & $\left(10.750, c_{1-3}, 14.955\right)$ & $\left(12.450, c_{1-8}, 16.900\right)$ & $\left(13.405, c_{1-15}, 18.355\right)$ & $\left(15.103, c_{1-20}, 21.750\right)$ & $\left(11.700, c_{1-26}, 16.825\right)$ \\
\hline facility 1 & $c_{1-3} \sim N(12.500,4)$ & $c_{1-8} \sim N(14.500,4)$ & $c_{1-15} \sim N(16.205,5)$ & $c_{1-20} \sim N(18.600,6)$ & $c_{1-26} \sim N(14.125,5)$ \\
\hline \multirow{2}{*}{$\begin{array}{c}\text { Fixed } \\
\text { facility } 3 \\
\end{array}$} & $\left(12.350, c_{3-3}, 16.500\right)$ & $\left(16.250, c_{3-8}, 20.900\right)$ & $\left(10.650, c_{3-15}, 15.705\right)$ & $\left(13.500, c_{3-20}, 17.450\right)$ & $\left(11.450, c_{3-26}, 16.720\right)$ \\
\hline & $c_{3-3} \sim N(14.135,6)$ & $c_{3-8} \sim N(18.015,4)$ & $c_{3-15} \sim N(12.135,5)$ & $c_{3-20} \sim N(15.175,4)$ & $c_{3-26} \sim N(14.100,5)$ \\
\hline \multicolumn{6}{|c|}{ The unit risk (unit:10 ${ }^{-6}$ person) } \\
\hline$\tilde{\bar{r}}_{m n}$ or $\tilde{\bar{r}}_{m f}$ & PFL 3 & PFL 8 & PFL 15 & PFL 20 & PFL 26 \\
\hline PFL 1 & $\left(3.517, f_{1-3}, 5.750\right)$ & $\left(2.160, f_{1-8}, 5.320\right)$ & $\left(3.610, f_{1-15}, 6.125\right)$ & $\left(6.750, f_{1-20}, 10.135\right)$ & $\left(4.325, f_{1-26}, 7.790\right)$ \\
\hline PFL 10 & $\begin{array}{c}f_{1-3} \sim N(4.250,2) \\
\left(4.500, f_{10-3}, 6.900\right) \\
f_{10-3} \sim N(5.255,3)\end{array}$ & $\begin{array}{c}f_{1-8} \sim N(3.350,3) \\
\left(9.700, f_{10-8}, 13.250\right) \\
f_{10-8} \sim N(11.755,4)\end{array}$ & $\begin{array}{l}f_{1-15} \sim N(4.425,3) \\
\left(3.450, f_{10-15}, 8.255\right) \\
f_{10-15} \sim N(5.460,5)\end{array}$ & $\begin{array}{l}f_{1-20} \sim N(8.300,4) \\
\left(3.350, f_{10-20}, 7.700\right) \\
f_{10-20} \sim N(4.900,4)\end{array}$ & $\begin{array}{c}f_{1-26} \sim N(5.325,4) \\
\left(6.500, f_{10-26}, 9.450\right) \\
f_{10-26} \sim N(8.150,3)\end{array}$ \\
\hline Fixed & $\left(6.980, e_{1-3}, 10.200\right)$ & $\left(7.800, e_{1-8}, 10.355\right)$ & $\left(4.755, e_{1-15}, 7.760\right)$ & $\left(6.805, e_{1-20}, 9.900\right)$ & $\left(2.330, e_{1-26}, 4.990\right)$ \\
\hline facility 1 & $e_{1-3} \sim N(8.505,4)$ & $e_{1-8} \sim N(9.250,3)$ & $e_{1-15} \sim N(5.900,3)$ & $e_{1-20} \sim N(7.500,3)$ & $e_{1-26} \sim N(3.355,3)$ \\
\hline Fixed & $\left(3.500, e_{3-3}, 7.750\right)$ & $\left(5.350, e_{3-8}, 10.050\right)$ & $\left(4.015, e_{3-15}, 7.070\right)$ & $\left(4.900, e_{3-20}, 7.520\right)$ & $\left(4.950, e_{3-26}, 8.550\right)$ \\
\hline facility 3 & $e_{3-3} \sim N(5.350,4)$ & $e_{3-8} \sim N(7.320,5)$ & $e_{3-15} \sim N(6.250,3)$ & $e_{3-20} \sim N(6.235,3)$ & $e_{3-26} \sim N(7.250,4)$ \\
\hline
\end{tabular}


Table 6: Satisfactory solutions for the general contractor and the subcontractor

\begin{tabular}{|c|c|c|c|c|c|c|c|c|c|c|c|c|c|c|c|c|c|c|c|c|c|c|c|c|c|c|c|}
\hline \multirow[b]{2}{*}{ Objectives } & \multirow[b]{2}{*}{ Solutions } & \multirow{2}{*}{$\begin{array}{l}\text { CTFs, PLFs or } \\
\text { Fixed } \\
\text { facilities }\end{array}$} & \multicolumn{21}{|c|}{ PFLs No. } & \multicolumn{4}{|c|}{ Fixed facilities No. } \\
\hline & & & 1234567891 & 1011 & 1112 & & & 1415 & 16 & 17 & 18 & 19 & 20 & 21 & 22 & 23 & 24 & 25 & 26 & 27 & 28 & 29 & 30 & 1 & 2 & 3 & 4 \\
\hline \multirow{18}{*}{$\begin{array}{l}\text { Best Cost }=8.0125 ; \\
\text { Average Cost }=8.2267 ; \\
\text { Worst Cost }=8.3565 \\
\left(10^{8} R M B\right)\end{array}$} & \multirow{18}{*}{$\mathrm{X}_{\mathrm{im}}$} & CTF 1 & $\begin{array}{lllllllllll}0 & 0 & 0 & 0 & 0 & 0 & 0 & 0 & 0 & 0\end{array}$ & $0 \quad 0$ & $0 \quad 0$ & $0 \quad 0$ & $0 \quad 0$ & $0 \quad 0$ & 0 & 0 & 0 & 0 & 0 & 0 & 0 & 0 & 0 & 0 & 1 & 0 & 0 & 0 & 0 & N/A & $\mathrm{N} / \mathrm{A}$ & $\mathrm{N} / \mathrm{A}$ & N/A \\
\hline & & CTF 2 & $\begin{array}{llllllllll}0 & 1 & 0 & 0 & 0 & 0 & 0 & 0 & 0 & 0\end{array}$ & $0 \quad 0$ & $0 \quad 0$ & $0 \quad 0$ & $0 \quad 0$ & $0 \quad 0$ & 0 & 0 & 0 & 0 & 0 & 0 & 0 & 0 & 0 & 0 & 0 & 0 & 0 & 0 & 0 & N/A & $\mathrm{N} / \mathrm{A}$ & N/A & N/A \\
\hline & & CTF 3 & $\begin{array}{llllllllll}0 & 0 & 0 & 0 & 0 & 0 & 0 & 0 & 0 & 0\end{array}$ & $0 \quad 0$ & $0 \quad 0$ & $0 \quad 0$ & $0 \quad 0$ & $0 \quad 0$ & 1 & 0 & 0 & 0 & 0 & 0 & 0 & 0 & 0 & 0 & 0 & 0 & 0 & 0 & 0 & N/A & N/A & N/A & N/A \\
\hline & & CTF 4 & $\begin{array}{llllllllll}0 & 0 & 0 & 0 & 0 & 0 & 0 & 0 & 0 & 0\end{array}$ & $0 \quad 0$ & $0 \quad 0$ & $0 \quad 1$ & 10 & $0 \quad 0$ & 0 & 0 & 0 & 0 & 0 & 0 & 0 & 0 & 0 & 0 & 0 & 0 & 0 & 0 & 0 & $\mathrm{~N} / \mathrm{A}$ & $\mathrm{N} / \mathrm{A}$ & $\mathrm{N} / \mathrm{A}$ & $\mathrm{N} / \mathrm{A}$ \\
\hline & & CTF 5 & $\begin{array}{llllllllll}0 & 0 & 0 & 0 & 0 & 1 & 0 & 0 & 0 & 0\end{array}$ & $0 \quad 0$ & $0 \quad 0$ & $0 \quad 0$ & $0 \quad 0$ & $0 \quad 0$ & 0 & 0 & 0 & 0 & 0 & 0 & 0 & 0 & 0 & 0 & 0 & 0 & 0 & 0 & 0 & N/A & $\mathrm{N} / \mathrm{A}$ & N/A & N/A \\
\hline & & CTF 6 & $\begin{array}{llllllllll}0 & 0 & 0 & 0 & 0 & 0 & 0 & 1 & 0 & 0\end{array}$ & $0 \quad 0$ & $0 \quad 0$ & $0 \quad 0$ & $0 \quad 0$ & $0 \quad 0$ & 0 & 0 & 0 & 0 & 0 & 0 & 0 & 0 & 0 & 0 & 0 & 0 & 0 & 0 & 0 & N/A & $\mathrm{N} / \mathrm{A}$ & $\mathrm{N} / \mathrm{A}$ & N/A \\
\hline & & CTF 7 & $\begin{array}{llllllllll}0 & 0 & 0 & 0 & 0 & 0 & 0 & 0 & 0 & 0\end{array}$ & $0 \quad 0$ & $0 \quad 0$ & $0 \quad 0$ & $0 \quad 0$ & $0 \quad 0$ & 0 & 0 & 1 & 0 & 0 & 0 & 0 & 0 & 0 & 0 & 0 & 0 & 0 & 0 & 0 & N/A & $\mathrm{N} / \mathrm{A}$ & $\mathrm{N} / \mathrm{A}$ & N/A \\
\hline & & CTF 8 & $\begin{array}{lllllllllll}0 & 0 & 0 & 0 & 0 & 0 & 0 & 0 & 0 & 0\end{array}$ & $0 \quad 0$ & $0 \quad 0$ & $0 \quad 0$ & $0 \quad 0$ & $0 \quad 0$ & 0 & 0 & 0 & 0 & 0 & 0 & 0 & 0 & 0 & 0 & 0 & 0 & 1 & 0 & 0 & N/A & $\mathrm{N} / \mathrm{A}$ & $\mathrm{N} / \mathrm{A}$ & $\mathrm{N} / \mathrm{A}$ \\
\hline & & CTF 9 & $\begin{array}{llllllllll}0 & 0 & 0 & 0 & 0 & 0 & 0 & 0 & 0 & 0\end{array}$ & $0 \quad 0$ & $0 \quad 0$ & $0 \quad 0$ & $0 \quad 0$ & $0 \quad 0$ & 0 & 0 & 0 & 0 & 0 & 0 & 1 & 0 & 0 & 0 & 0 & 0 & 0 & 0 & 0 & N/A & N/A & N/A & N/A \\
\hline & & CTF 10 & $\begin{array}{llllllllll}0 & 0 & 0 & 0 & 0 & 0 & 0 & 0 & 0 & 0\end{array}$ & $0 \quad 0$ & $0 \quad 0$ & $0 \quad 0$ & $0 \quad 0$ & $0 \quad 1$ & 0 & 0 & 0 & 0 & 0 & 0 & 0 & 0 & 0 & 0 & 0 & 0 & 0 & 0 & 0 & N/A & N/A & $\mathrm{N} / \mathrm{A}$ & N/A \\
\hline & & CTF 11 & $\begin{array}{lllllllllll}0 & 0 & 3 & 0 & 0 & 0 & 0 & 0 & 0 & 0\end{array}$ & $0 \quad 0$ & $0 \quad 0$ & $0 \quad 0$ & $0 \quad 0$ & $0 \quad 0$ & 0 & 0 & 0 & 0 & 0 & 0 & 0 & 0 & 0 & 0 & 0 & 0 & 0 & 0 & 0 & N/A & $\mathrm{N} / \mathrm{A}$ & N/A & N/A \\
\hline & & CTF 12 & $\begin{array}{llllllllll}0 & 0 & 0 & 0 & 0 & 0 & 0 & 0 & 0 & 0\end{array}$ & $0 \quad 0$ & $0 \quad 1$ & 10 & $0 \quad 0$ & $0 \quad 0$ & 0 & 0 & 0 & 0 & 0 & 0 & 0 & 0 & 0 & 0 & 0 & 0 & 0 & 0 & 0 & N/A & N/A & N/A & N/A \\
\hline & & CTF 13 & $\begin{array}{llllllllll}0 & 0 & 0 & 0 & 0 & 0 & 0 & 0 & 0 & 0\end{array}$ & $0 \quad 0$ & $0 \quad 0$ & $0 \quad 0$ & $0 \quad 1$ & 10 & 0 & 0 & 0 & 0 & 0 & 0 & 0 & 0 & 0 & 0 & 0 & 0 & 0 & 0 & 0 & N/A & $\mathrm{N} / \mathrm{A}$ & N/A & N/A \\
\hline & & CTF 14 & $\begin{array}{lllllllllll}0 & 0 & 0 & 0 & 0 & 0 & 0 & 0 & 0 & 0\end{array}$ & $\begin{array}{ll}0 & 1\end{array}$ & 10 & $0 \quad 0$ & $0 \quad 0$ & 00 & 0 & 0 & 0 & 0 & 0 & 0 & 0 & 0 & 0 & 0 & 0 & 0 & 0 & 0 & 0 & $\mathrm{~N} / \mathrm{A}$ & $\mathrm{N} / \mathrm{A}$ & $\mathrm{N} / \mathrm{A}$ & $\mathrm{N} / \mathrm{A}$ \\
\hline & & CTF 15 & $\begin{array}{lllllllllll}0 & 0 & 0 & 0 & 0 & 0 & 0 & 0 & 0 & 0\end{array}$ & $0 \quad 0$ & $0 \quad 0$ & $0 \quad 0$ & $0 \quad 0$ & 00 & 0 & 0 & 0 & 1 & 0 & 0 & 0 & 0 & 0 & 0 & 0 & 0 & 0 & 0 & 0 & N/A & $\mathrm{N} / \mathrm{A}$ & $\mathrm{N} / \mathrm{A}$ & $\mathrm{N} / \mathrm{A}$ \\
\hline & & CTF 16 & $\begin{array}{lllllllllll}0 & 0 & 0 & 0 & 0 & 0 & 0 & 0 & 0 & 0\end{array}$ & $0 \quad 0$ & $0 \quad 0$ & $0 \quad 0$ & $0 \quad 0$ & 00 & 0 & 0 & 0 & 0 & 0 & 1 & 0 & 0 & 0 & 0 & 0 & 0 & 0 & 0 & 0 & $\mathrm{~N} / \mathrm{A}$ & $\mathrm{N} / \mathrm{A}$ & $\mathrm{N} / \mathrm{A}$ & $\mathrm{N} / \mathrm{A}$ \\
\hline & & CTF 17 & $\begin{array}{lllllllllll}0 & 0 & 0 & 0 & 0 & 0 & 0 & 0 & 0 & 0\end{array}$ & $0 \quad 0$ & $0 \quad 0$ & $0 \quad 0$ & $0 \quad 0$ & 00 & 0 & 0 & 0 & 0 & 0 & 0 & 0 & 0 & 0 & 0 & 0 & 1 & 0 & 0 & 0 & N/A & $\mathrm{N} / \mathrm{A}$ & $\mathrm{N} / \mathrm{A}$ & $\mathrm{N} / \mathrm{A}$ \\
\hline & & CTF 18 & $\begin{array}{llllllllll}0 & 0 & 0 & 0 & 0 & 0 & 0 & 0 & 0 & 0\end{array}$ & $0 \quad 0$ & $\begin{array}{ll}0 & 0\end{array}$ & $\begin{array}{ll}0 & 0\end{array}$ & $0 \quad 0$ & $0 \quad 0$ & 0 & 0 & 0 & 0 & 0 & 0 & 0 & 0 & 0 & 0 & 0 & 0 & 0 & 1 & 0 & N/A & $\mathrm{N} / \mathrm{A}$ & $\mathrm{N} / \mathrm{A}$ & N/A \\
\hline \multirow{34}{*}{$\begin{array}{l}\text { Best Cost }=2.3545 ; \\
\text { Average Cost }=2.4035 ; \\
\text { Worst Cost }=2.5647 \\
\left(10^{8} R M B\right) \\
\text { Best Risk }=567.557 ; \\
\text { Average Risk }=573.125 ; \\
\text { Worst Risk }=595.379\end{array}$} & & PFL 1 & $-\begin{array}{llllllllll}0 & 0 & 0 & 0 & 0 & 0 & 0 & 0 & 0\end{array}$ & $\begin{array}{ll}0 & 0\end{array}$ & $0 \quad 0$ & $\begin{array}{ll}0 & 0\end{array}$ & $0 \quad 0$ & 0 & 0 & 0 & 0 & 0 & 0 & 0 & 0 & 0 & 0 & 0 & 0 & 0 & 0 & 0 & 0 & - & - & - & - \\
\hline & & PFL 2 & - -1000000000 & $0 \quad 0$ & $0 \quad 0$ & $0 \quad 0$ & $0 \quad 0$ & $0 \quad 0$ & 0 & 0 & 0 & 0 & 0 & 0 & 0 & 0 & 0 & 0 & 0 & 0 & 0 & 1 & 0 & - & - & - & - \\
\hline & & PFL 3 & - $-\begin{array}{llllllll}- & 0 & 0 & 0 & 0 & 0 & 0 & 0\end{array}$ & $0 \quad 0$ & $0 \quad 0$ & $0 \quad 0$ & $0 \quad 0$ & 00 & 0 & 0 & 0 & 0 & 0 & 0 & 0 & 0 & 0 & 0 & 1 & 0 & 0 & 0 & 0 & - & - & - & - \\
\hline & & PFL 4 & $\ldots$ & $0 \quad 0$ & $0 \quad 0$ & $0 \quad 0$ & $0 \quad 0$ & $0 \quad 0$ & 0 & 0 & 0 & 0 & 0 & 0 & 0 & 0 & 0 & 0 & 0 & 0 & 0 & 0 & 0 & - & - & - & - \\
\hline & & PFL 5 & $\ldots$ & $0 \quad 0$ & $0 \quad 0$ & $0 \quad 0$ & $0 \quad 0$ & 00 & 0 & 0 & 0 & 0 & 0 & 0 & 0 & 0 & 0 & 0 & 0 & 0 & 0 & 0 & 0 & - & - & - & - \\
\hline & & PFL 6 & $\ldots \ldots$ & $0 \quad 0$ & $0 \quad 0$ & $0 \quad 0$ & $0 \quad 0$ & $0 \quad 0$ & 0 & 0 & 0 & 0 & 0 & 0 & 0 & 0 & 0 & 0 & 0 & 0 & 1 & 0 & 0 & - & - & - & - \\
\hline & & PFL 7 & $\cdots \cdots-\ldots 00$ & $0 \quad 0$ & $0 \quad 0$ & $0 \quad 0$ & $0 \quad 0$ & $0 \quad 0$ & 0 & 0 & 0 & 0 & 0 & 0 & 0 & 0 & 0 & 0 & 0 & 0 & 0 & 0 & 0 & - & - & - & - \\
\hline & & PFL 8 & $\ldots \ldots-\ldots 0$ & $\begin{array}{ll}0 & 0\end{array}$ & $0 \quad 0$ & $0 \quad 0$ & $0 \quad 0$ & $0 \quad 0$ & 0 & 0 & 0 & 0 & 0 & 0 & 0 & 0 & 0 & 0 & 0 & 0 & 0 & 0 & 0 & - & - & - & - \\
\hline & & PFL 9 & $\cdots \cdots-\ldots$ & $\begin{array}{ll}0 & 0\end{array}$ & $0 \quad 0$ & $\begin{array}{ll}0 & 0\end{array}$ & $0 \quad 0$ & $0 \quad 0$ & 0 & 0 & 0 & 0 & 0 & 0 & 0 & 0 & 0 & 0 & 0 & 0 & 0 & 0 & 0 & - & - & - & - \\
\hline & & PFL 10 & $---\cdot--\cdot-$ & -0 & 00 & $0 \quad 0$ & $0 \quad 0$ & $0 \quad 0$ & 0 & 0 & 0 & 0 & 0 & 0 & 0 & 0 & 0 & 0 & 0 & 0 & 0 & 0 & 0 & - & - & - & - \\
\hline & & PFL 11 & $-\ldots-\ldots-\ldots$ & $-\quad-$ & -0 & $\begin{array}{ll}0 & 0\end{array}$ & $\begin{array}{ll}0 & 1\end{array}$ & 10 & 0 & 0 & 0 & 0 & 0 & 0 & 0 & 0 & 0 & 0 & 1 & 0 & 0 & 0 & 0 & - & - & - & - \\
\hline & & PFL 12 & $---\cdot---$ & $-\quad-$ & $-\quad-$ & -0 & $0 \quad 0$ & $0 \quad 0$ & 0 & 0 & 0 & 0 & 0 & 0 & 0 & 0 & 0 & 0 & 0 & 0 & 0 & 0 & 0 & - & - & - & - \\
\hline & & PFL 13 & $-\ldots-\ldots$ & $-\quad-$ & - - & - - & -0 & $0 \quad 1$ & 0 & 0 & 0 & 0 & 0 & 0 & 0 & 0 & 0 & 0 & 0 & 0 & 0 & 0 & 0 & - & - & - & - \\
\hline & & PFL 14 & $-\ldots-\ldots$ & $-\quad-$ & - - & $-\quad-$ & $-\quad-$ & -0 & 0 & 0 & 0 & 0 & 0 & 0 & 0 & 0 & 0 & 0 & 0 & 0 & 0 & 0 & 0 & - & - & - & - \\
\hline & & PFL 15 & $-\ldots-\ldots--$ & $-\quad-$ & $-\quad-$ & $-\quad-$ & $-\quad-$ & $-\quad-$ & 1 & 0 & 0 & 0 & 0 & 0 & 0 & 0 & 0 & 0 & 0 & 0 & 0 & 0 & 0 & - & - & - & - \\
\hline & $y_{\mathrm{mn}}$ & PFL 16 & $\ldots \ldots-\ldots$ & $-\quad-$ & $-\quad-$ & $-\quad-$ & - & $-\quad-$ & - & 0 & 1 & 0 & 0 & 1 & 0 & 0 & 0 & 0 & 0 & 0 & 0 & 0 & 0 & - & - & - & - \\
\hline & & PFL 17 & $-\ldots-\ldots$ & - - & - - & - - & $-\quad-$ & $-\quad-$ & - & - & 0 & 0 & 0 & 0 & 0 & 0 & 0 & 0 & 0 & 0 & 0 & 0 & 0 & - & - & - & - \\
\hline & & PFL 18 & $\ldots-\ldots-\ldots$ & - - & - - & - - & $-\quad-$ & $-\quad-$ & - & - & - & 0 & 0 & 0 & 0 & 0 & 0 & 0 & 0 & 0 & 0 & 0 & 0 & - & - & - & - \\
\hline & & PFL 19 & $-\ldots \ldots$ & $-\quad-$ & $-\quad-$ & $-\quad-$ & $-\quad-$ & $-\quad-$ & - & - & - & - & 0 & 0 & 1 & 0 & 0 & 0 & 0 & 0 & 0 & 0 & 0 & - & - & - & - \\
\hline & & PFL 20 & $\ldots-\ldots$ & $-\quad-$ & $-\quad-$ & $-\quad-$ & $-\quad-$ & $-\quad-$ & - & - & - & - & - & 0 & 0 & 0 & 0 & 0 & 0 & 0 & 0 & 0 & 0 & - & - & - & - \\
\hline & & PFL 21 & $-\ldots-\ldots$ & $-\quad-$ & $-\quad-$ & $-\quad-$ & $-\quad-$ & $-\quad-$ & - & - & - & - & - & - & 1 & 0 & 0 & 0 & 0 & 0 & 0 & 0 & 0 & - & - & - & - \\
\hline & & PFL 22 & - . - . - - - & $-\quad-$ & $-\quad-$ & $-\quad-$ & $-\quad-$ & $-\quad-$ & - & - & - & - & - & - & - & 0 & 0 & 0 & 0 & 0 & 0 & 0 & 0 & - & - & - & - \\
\hline & & PFL 23 & $-\ldots-\ldots$ & $-\quad-$ & $-\quad-$ & $-\quad-$ & $-\quad-$ & $-\quad-$ & - & - & - & - & - & - & - & - & 0 & 0 & 0 & 0 & 0 & 0 & 0 & - & - & - & - \\
\hline & & PFL 24 & $-\ldots-\ldots$ & $-\quad-$ & $-\quad-$ & $-\quad-$ & $-\quad-$ & $-\quad-$ & - & - & - & - & - & - & - & - & - & 0 & 0 & 0 & 0 & 0 & 0 & - & - & - & - \\
\hline & & PFL 25 & $-\ldots-\ldots$ & $-\quad-$ & $-\quad-$ & $-\quad-$ & $-\quad-$ & $-\quad-$ & - & - & - & - & - & - & - & - & - & - & 0 & 0 & 0 & 0 & 0 & - & - & - & - \\
\hline & & PFL 26 & $\ldots-\ldots$ & $-\quad-$ & $-\quad-$ & $-\quad-$ & $-\quad-$ & $-\quad-$ & - & - & - & - & - & - & - & - & - & - & - & 0 & 0 & 0 & 0 & - & - & - & - \\
\hline & & PFL 27 & $\ldots-\ldots$ & $-\quad-$ & $-\quad-$ & $-\quad-$ & $-\quad-$ & $-\quad-$ & - & - & - & - & - & - & - & - & - & - & - & - & 1 & 0 & 0 & - & - & - & - \\
\hline & & PFL 28 & $-\ldots-\ldots--$ & $-\quad-$ & $-\quad-$ & $-\quad-$ & $-\quad-$ & $-\quad-$ & - & - & - & - & - & - & - & - & - & - & - & - & - & 0 & 0 & - & - & - & - \\
\hline & & PFL 29 & $---\cdot---$ & $-\quad-$ & $-\quad-$ & $-\quad-$ & $-\quad-$ & $-\quad-$ & - & - & - & - & - & - & - & - & - & - & - & - & - & - & 0 & - & - & - & - \\
\hline & & PFL 30 & $-\ldots-\ldots-\ldots$ & $-\quad-$ & $-\quad-$ & $-\quad-$ & $-\quad-$ & - & - & - & - & - & - & - & - & - & - & - & - & - & - & - & - & - & - & - & - \\
\hline & & $\begin{array}{c}\text { Fixed } \\
\text { facility } 1\end{array}$ & $\begin{array}{llllllllll}0 & 0 & 0 & 0 & 0 & 1 & 0 & 0 & 0 & 0\end{array}$ & $0 \quad 0$ & $0 \quad 0$ & $0 \quad 0$ & $0 \quad 0$ & 00 & 0 & 0 & 0 & 0 & 0 & 0 & 0 & 0 & 0 & 0 & 0 & 0 & 0 & 0 & 0 & - & 1 & 1 & 0 \\
\hline & & $\begin{array}{c}\text { Fixed } \\
\text { facility } 2\end{array}$ & $\begin{array}{llllllllll}0 & 0 & 0 & 0 & 0 & 0 & 0 & 0 & 0 & 0\end{array}$ & $\begin{array}{ll}0 & 1\end{array}$ & 11 & 10 & $0 \quad 0$ & 00 & 0 & 0 & 0 & 0 & 0 & 1 & 0 & 0 & 0 & 0 & 0 & 0 & 0 & 1 & 0 & - & - & 0 & 0 \\
\hline & $9 \mathrm{mI}$ & $\begin{array}{c}\text { Fixed } \\
\text { facility } 3\end{array}$ & $\begin{array}{lllllllllll}0 & 0 & 0 & 0 & 0 & 0 & 0 & 1 & 0 & 0\end{array}$ & $0 \quad 0$ & $0 \quad 0$ & $0 \quad 0$ & $0 \quad 0$ & 00 & 0 & 0 & 0 & 0 & 0 & 0 & 0 & 0 & 0 & 0 & 0 & 0 & 0 & 0 & 0 & - & - & - & 1 \\
\hline & & $\begin{array}{l}\text { Fixed } \\
\text { facility } 4\end{array}$ & $\begin{array}{llllllllll}0 & 0 & 0 & 0 & 0 & 0 & 0 & 0 & 0 & 0\end{array}$ & $\begin{array}{ll}0 & 0\end{array}$ & $\begin{array}{ll}0 & 0\end{array}$ & $\begin{array}{ll}0 & 1\end{array}$ & 10 & $0 \quad 0$ & 0 & 0 & 0 & 0 & 0 & 0 & 0 & 0 & 0 & 0 & 0 & 0 & 0 & 0 & 0 & - & - & - & - \\
\hline
\end{tabular}


Table 7: Satisfactory solutions for the general contractor and the subcontractor based on different models and algorithm methods

\begin{tabular}{|c|c|c|c|c|c|c|c|c|c|c|}
\hline \multicolumn{2}{|c|}{ Comparison items } & \multicolumn{3}{|c|}{ The general contractor } & \multicolumn{6}{|c|}{ The subcontractor } \\
\hline & & $\begin{array}{c}\text { Best cost } \\
\left(10^{8} R M B\right)\end{array}$ & $\begin{array}{c}\text { Average } \\
\text { cost } \\
\left(10^{8} R M B\right)\end{array}$ & $\begin{array}{c}\text { Worst } \\
\text { cost } \\
\left(10^{8} R M B\right) \\
\end{array}$ & $\begin{array}{l}\text { Best cost } \\
\left(10^{8} R M B\right)\end{array}$ & $\begin{array}{c}\text { Average } \\
\text { cost } \\
\left(10^{8} R M B\right)\end{array}$ & $\begin{array}{c}\text { Worst cost } \\
\left(10^{8} R M B\right)\end{array}$ & Best risk & $\begin{array}{c}\text { Average } \\
\text { risk }\end{array}$ & Worst risk \\
\hline \multirow[t]{2}{*}{ Models } & eq. [12] & 8.0125 & 8.2267 & 8.3565 & 2.3545 & 2.4035 & 2.5647 & 567.557 & 573.125 & 595.379 \\
\hline & eq.[17] & 7.9776 & 8.1557 & 8.2975 & N/A & N/A & N/A & N/A & $\mathrm{N} / \mathrm{A}$ & N/A \\
\hline \multirow[t]{3}{*}{ Methods } & $\begin{array}{c}\text { HGABPS } \\
\text { O }\end{array}$ & 8.0125 & 8.2267 & 8.3565 & 2.3545 & 2.4035 & 2.5647 & 567.557 & 573.125 & 595.379 \\
\hline & BPSO & 8.3497 & 8.6750 & 8.8065 & 2.3998 & 2.4755 & 2.7950 & 571.350 & 579.230 & 596.900 \\
\hline & GA & 8.7557 & 8.8258 & 9.2695 & 2.4796 & 2.5115 & 2.7355 & 577.395 & 581.735 & 599.250 \\
\hline
\end{tabular}




\section{FIGURE CAPTIONS}

Figure 1: The practical CTFLP with conflicts between the CTFLP and the TRP

Figure 2: The conflicts identification between the general contractor and subcontractor with uncertainty

Figure 3: The whole process of employing FRVs in the general contractor-subcontractor structure

Figure 4: The process of estimating $a_{1}$ and $a_{2}$

Figure 5: the operation process of the HGABPSO in solving eq. [12]

Figure 6: The practical situation for Hydropower A

Figure 7: The applied method for collecting FRVs for eq. [12]

Figure 8: The satisfactory solutions for the general contractor-subcontractor structure

Figure 9: The different convergence trends for HGABPSO, GA and PSO 


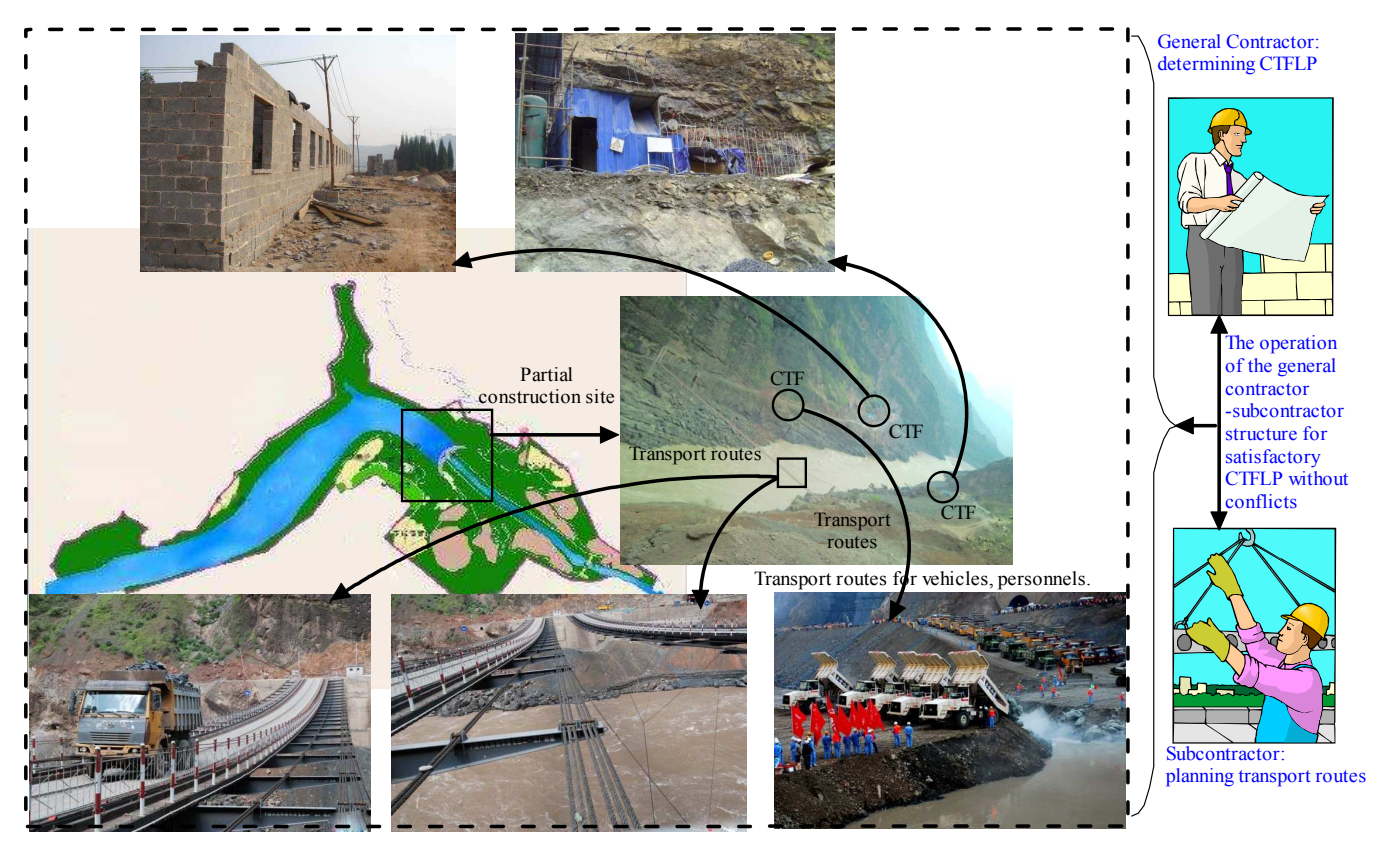




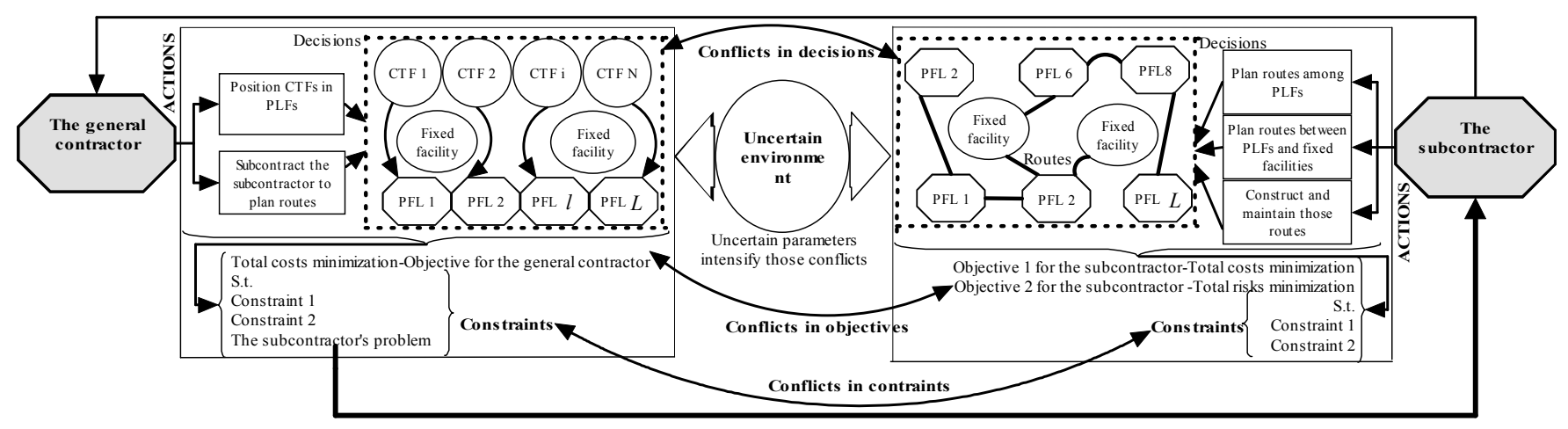




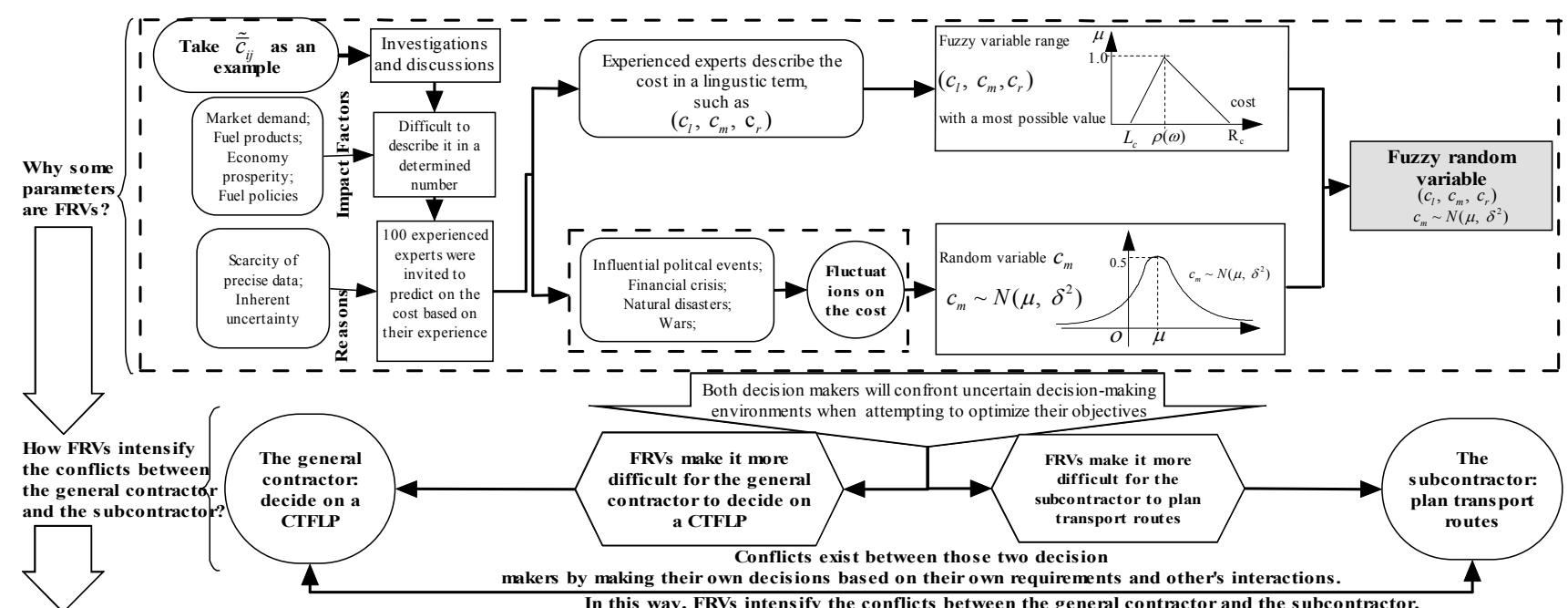

Thus, considering FRVs are helpful for decreasing and resolving the conflict. 


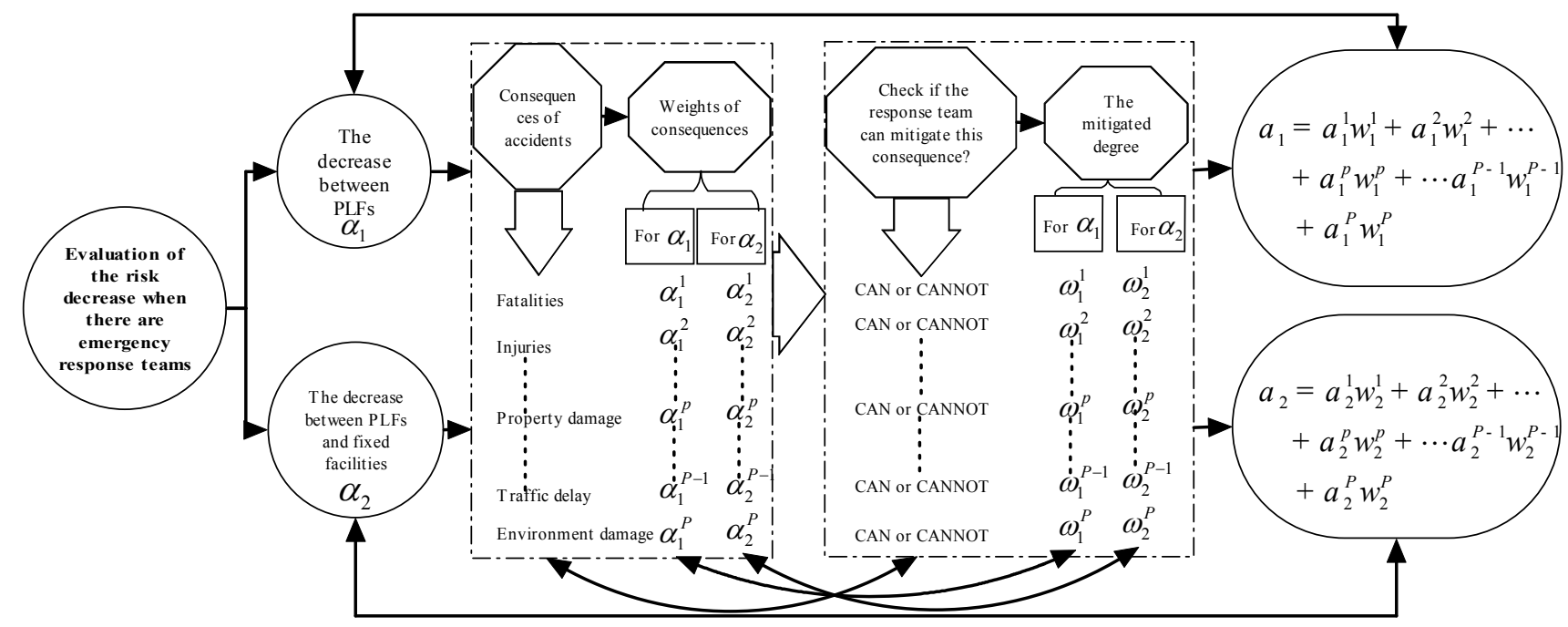




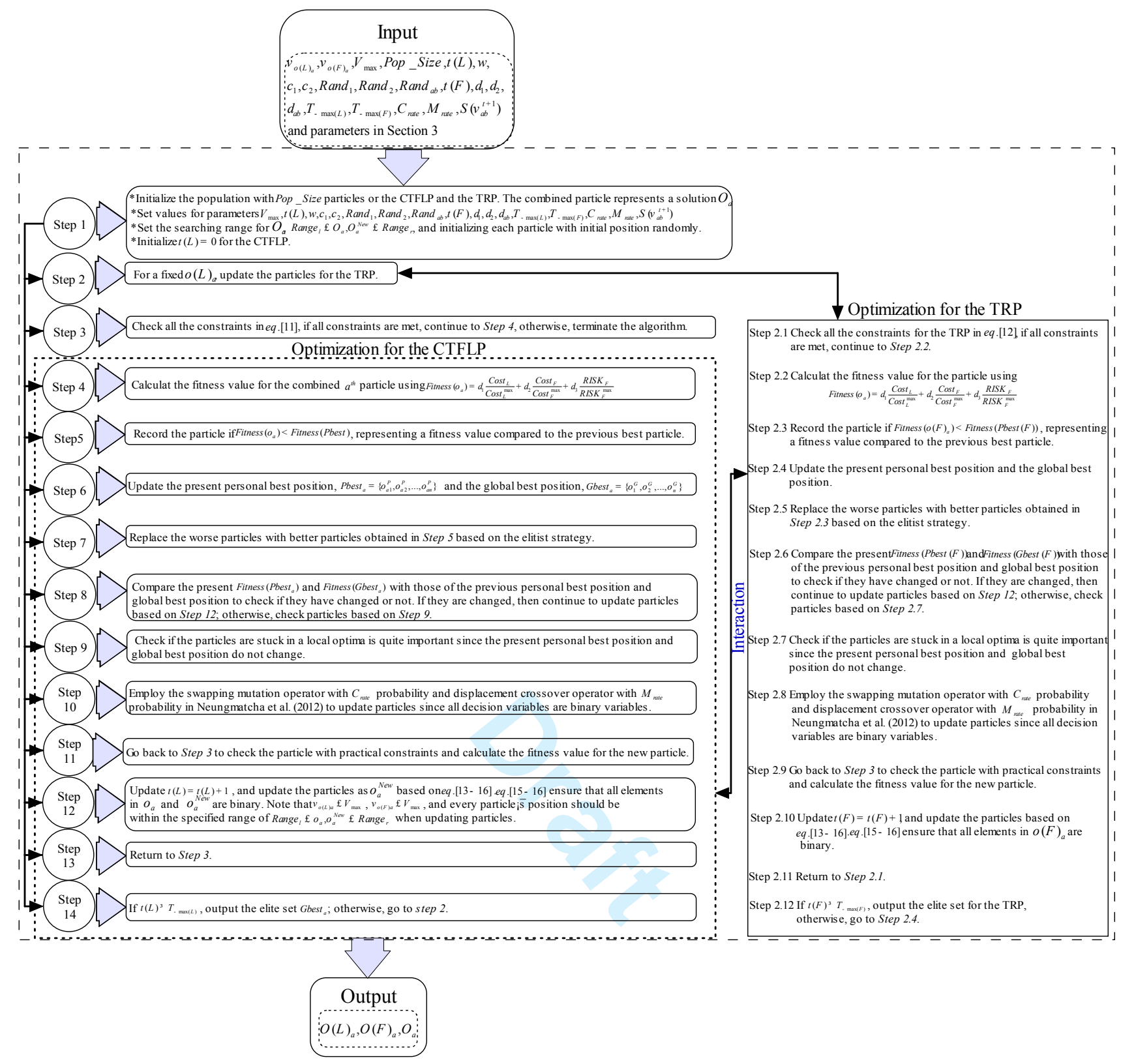




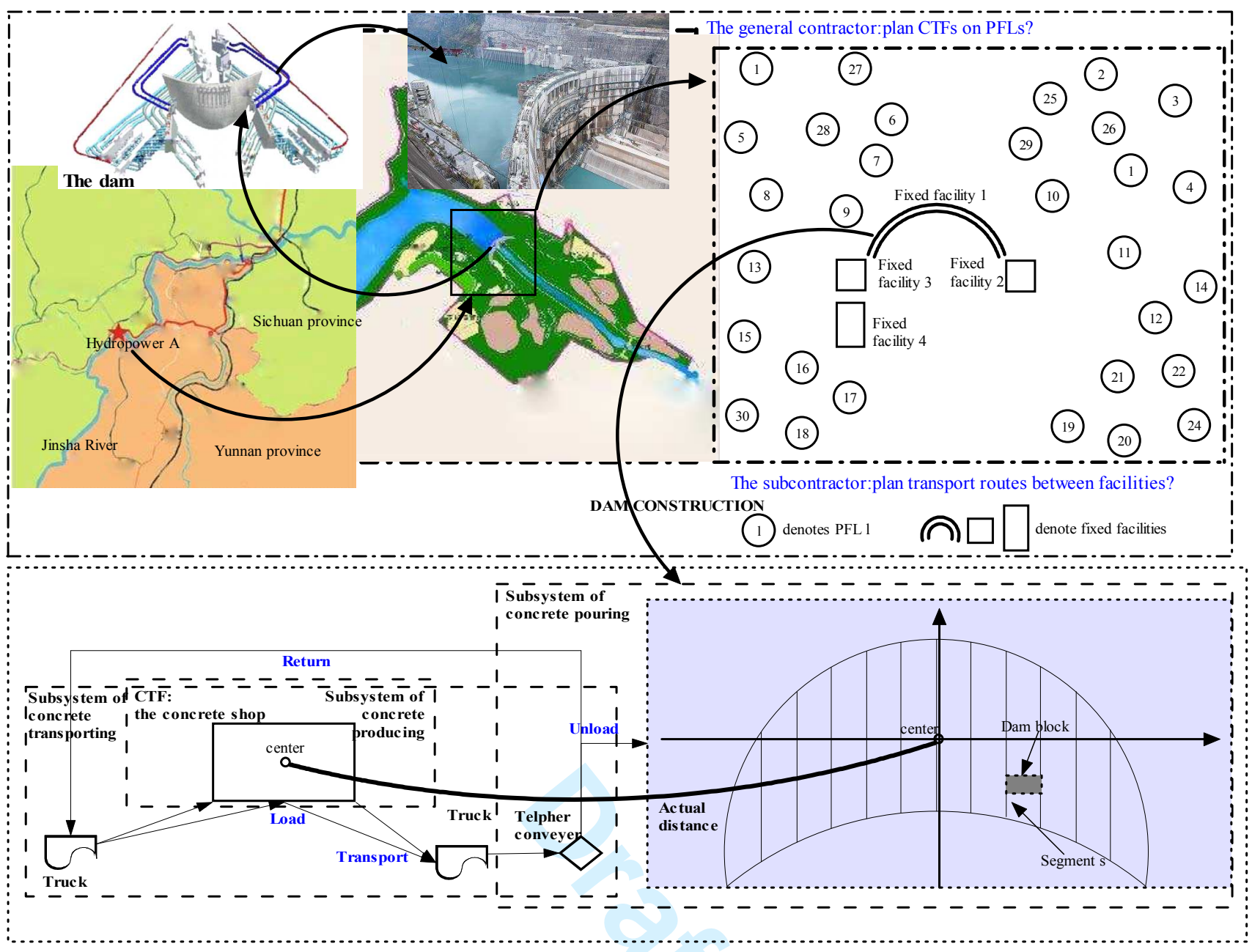




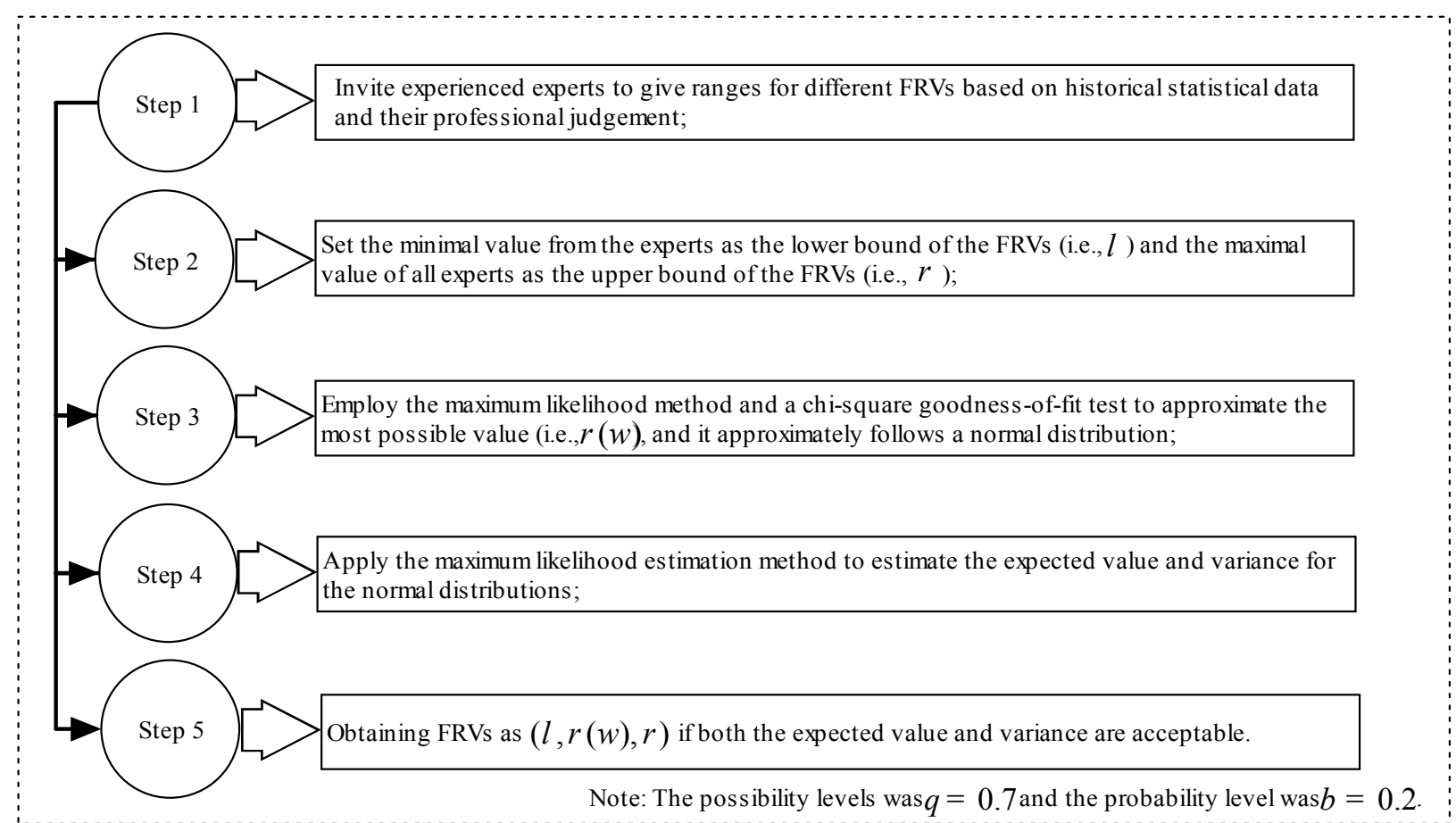









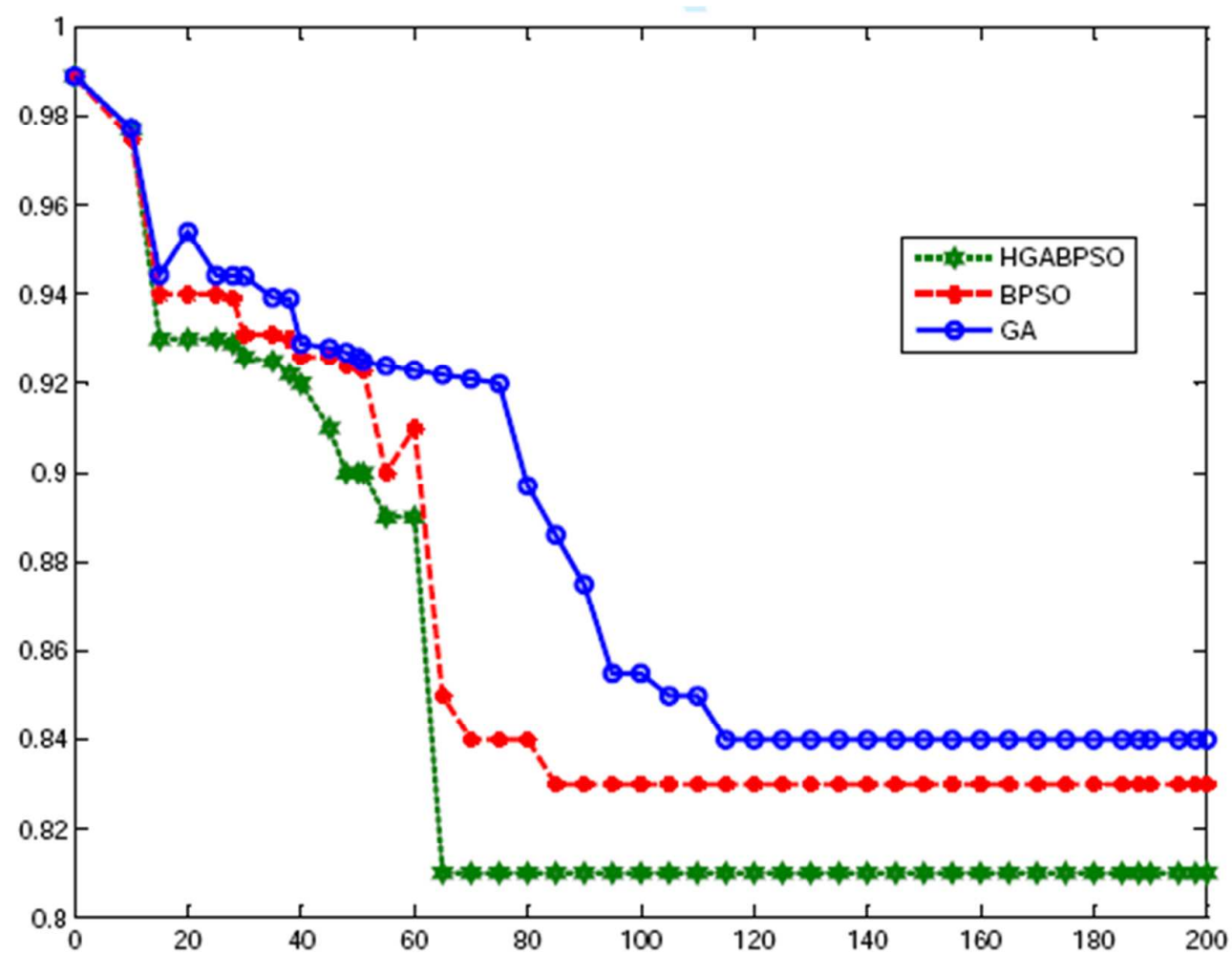

